\title{
Climate-Related Variation in Body Dimensions within Four Lacertid Species
}

\author{
Stanislav Volynchik \\ The Steinhardt Museum of Natural History and National Research Center, Department of Zoology, \\ Faculty of Life Sciences, Tel Aviv University, 6997801 Tel Aviv, Israel \\ Correspondence should be addressed to Stanislav Volynchik; stanislav_volynchik@yahoo.com
}

Received 17 December 2013; Revised 9 April 2014; Accepted 15 April 2014; Published 19 May 2014

Academic Editor: Michel Laurin

Copyright (C) 2014 Stanislav Volynchik. This is an open access article distributed under the Creative Commons Attribution License, which permits unrestricted use, distribution, and reproduction in any medium, provided the original work is properly cited.

A close relationship between habitat and external morphology is widespread among many animals, including reptiles. Here, I studied the relationship between abiotic environmental conditions and body size of four lacertid species (Phoenicolacerta laevis, Ophisops elegans, Acanthodactylus boskianus, and Mesalina guttulata) occurring in Israel. I examined the effect of average annual temperature and average annual precipitation on body and limb dimensions, using linear statistical models. Temperatureand precipitation-related geographic clines in body size showed the same trend among all species. Females displayed stronger phenotypic response to temperature gradient than conspecific males, suggesting a sex-specific effect of natural selection. Snoutvent length (SVL) was negatively correlated with temperature, supporting Bergmann's rule in O. elegans and in female P. laevis and A. boskianus, but not in M. guttulata. Precipitation was positively related to SVL in O. elegans and M. guttulata, and in female P. laevis and $A$. boskianus. The relative extremity lengths, especially hind limb segments, generally increase towards hot and dry locations, following Allen's rule. Among the Mediterranean region species (P. laevis, O. elegans) the morphological-environmental link with temperature was stronger than in desert dwellers (A. boskianus, M. guttulata), for which precipitation was the major determinant of spatial variation.

\section{Introduction}

Latitudinal variation in corporeal dimensions has often been explained as a response to temperature gradients, which are strong predictors of animals' external morphology. Zoogeographic principles such as Bergmann's and Allen's rules, in classical (thermal) interpretation, express the relationship between body size or shape and environmental temperature [1]. Therefore, the most renowned and generally accepted explanation for these rules is based on the heat-conservation hypothesis [2-4]: reduced surface area-to-volume ratio provides better heat retention in order to reduce body heat loss at low temperatures (Bergmann's rule). Bergmann [5] stated that in cooler climates, large-bodied endotherms, with a low body surface area to body volume ratio (i.e., a greater thermal inertia), typically retain body heat better than smaller ones. Similar principles contributing to reduce heat loss underlie Allen's rule [6], which predicted that animals living in colder environments tend to have shorter protruding body parts, such as ears, tails, and limbs. Furthermore, several authors
$[7,8]$ have shown that the geographical intraspecific variation in corporeal dimensions of homeotherms has been related to either ambient temperature or moisture, or both. On the whole, there is evidence showing the link between phenotypic plasticity and food availability, that is, the "resource rule" [911], depending, in turn, on a complex of climatic (mainly water- and temperature-related) parameters. Yom-Tov and Nix [12] concluded that in some Australian mammals precipitation, which mostly contributes to primary production in hot and dry habitats, is often better correlated with body size than is temperature. Therefore, food resources constitute the major factor determining body size variation. Recently, Pincheira-Donoso and Meiri [13] based on an intercontinental dataset (65 reptile species from Israel, Argentina, and Chile) found that for both Israeli and South American squamates the resource rule is better predictor of body size than temperature.

Multiple studies have noted that many tetrapods show size-latitude gradients. Clines in body dimensions have been well documented among many mammals, reptiles, and 
amphibians [14-16]. In reptiles, even earlier investigations [9] based on species assemblages have revealed that, in general, they do not exhibit noticeable latitudinal trends, although some snake taxa show a weak gradient. However, the appearance of spatial trends in body size for ectotherms [2], including vertebrates [17-19], is still disputed [13, 20-23]. In recent years, many studies have tested Bergmann's rule for various ectotherm taxa and have found a wide range of patterns depicting the connection between body size and environmental gradient [16, 18, 24-27]. Atkinson and Sibly [28] and Cruz et al. [29] have claimed that some ectotherms follow Bergmann's rule, whereas for other species the opposite pattern is true [30,31]. Ashton and Feldman [17] found that turtles follow Bergmann's rule whereas squamates contrast it. Cruz et al. [29] demonstrated a strong negative temperaturebody size gradient among Liolaemus lizard species, reflecting a profound effect of thermal inertia at higher latitudes or altitudes, in accordance with Bergmann's rule. However, Pincheira-Donoso et al. [20,32] within the same lineage, but based on an enlarged sample size, failed to find statistical support for Bergmann's clines and, claiming that in these animals the evolution of larger bodies in colder areas is disadvantageous, they suggested that it applied exclusively to endotherms. It is possible that the spatial trends in body dimensions are influenced by a complex set of both abiotic (e.g., seasonality and temperature) and biotic (e.g., intraand interspecific competition) factors and their interactions $[17,18,33]$ and that no single mechanism can explain them.

However, to my knowledge, some important issues remain obscure. For instance, tests of intraspecific body size or shape patterns in squamates accounting for gender-specific aspects are scarce because the papers often provide data for the pooled male and female samples. Taking into account that reptiles are often sexually dimorphic $([34,35]$ see also the results) it is possible that conclusions of some ecogeographic studies may suffer from biased sampling. In this context, my primary goal is to compare the sexes in respect to their relationship with climate variables. A nonphylogenetic approach was used here to test the main hypothesis that males and females facing different thermal and metabolic demands follow different patterns in their phenotypic responses to environmental gradient. Further, I evaluate the combined effect of temperature and precipitation on body dimensions within all the species studied. Finally, I also focus on speciesspecific peculiarities in the appearance of environmentally related phenotypic variation. Diurnal lizards including aridzone dwellers bask in large amounts of time, especially in the morning hours (personal observations). Under this scenario, I hypothesize that in the desert M. guttulata and A. boskianus, which are affected by exposure to extreme daily temperature fluctuations, a smaller size is likely to be preferable. Smallbodied individuals may have better heating and cooling abilities, heating faster after the cold nights, and can thus remain active for longer periods. It is generally accepted $[36,37]$ that temperature is the most important factor influencing lizards' activities and that thermal demands play an important role in habitat selection by reptiles. In the wild, lizards apply a variety of strategies to achieve their preferred body temperature. Thermoregulation is realized behaviourally through shuttling between warm and cold sites [38], as well as physiologically by altering peripheral blood flow and modifying heart rates $[39,40]$. In addition, some species apply ventilatory heat loss $[41,42]$ via evaporation through their mouth or cloaca.

In arid areas, where the present study mainly took place, rainfall, as well as temperature, is an important factor in animal ecology, including determining food availability and thus also growth rate [11]. The dispute over which geographic component determines body size most makes an examination of the respective influence of temperature- and water-related variables on morphological features timely. In the present study, I used a range of linear measurements and ratios in four oviparous lizard species in order to determine the correlation between morphology, temperature, and precipitation. I examined environmentally induced phenotypic variability and the validity of ecomorphological patterns, such as Bergmann's and Allen's rules, in four Middle-Eastern wideranging lacertid lizards: Phoenicolacerta laevis, Ophisops elegans, Acanthodactylus boskianus, and Mesalina guttulata.

Acanthodactylus and Mesalina species are mainly desert inhabitants, while the Phoenicolacerta and Ophisops species mostly inhabit the Mediterranean region (a more mesic area). In Israel these species occur along pronounced temperature and rainfall gradients ([43] and see below), which makes this region a convenient model for examining intraspecific ecomorphological variation. Thus, in Israel mean annual rainfall ranges from $\sim 1000 \mathrm{~mm}$ in the north to $25 \mathrm{~mm}$ in the south. There is a negative north-south gradient in ambient temperature with annual averages of about $15^{\circ} \mathrm{C}$ and $25^{\circ} \mathrm{C}$ in the north and south, respectively. Another strong climatic feature is a U-shaped west/east temperature gradient from the temperate Mediterranean coast to the colder central mountain range, and the very hot Jordan Valley in the east (Figure 1). The daily and annual temperature fluctuations also differ greatly across Israel.

Israel, which has a wide range of climates and landscapes, including mountain regions, coastal plains, humid valleys, rocky deserts, and sand dunes, is a hotspot of reptile species richness [44]. Environmental temperatures (e.g., extreme annual/diurnal values) and rainfall intensity (Figures 1(a) and $1(b))$ are markedly different across the distribution ranges of both desert and the Mediterranean region species. Hence, the appearance of morphological variation in ectotherms is expected to be adjusted by species-specific ecological interactions leading to interspecific differences in body size (or shape) gradient. In this context, I expect a different link between both abiotic predictors and body/limb proportions within ecologically different lizard species. For example, temperature may be a stronger ecological determinant of body or extremities size variation for $P$. laevis and $O$. elegans living in cooler environments than for the desert $A$. boskianus and $M$. guttulata. The present study is the first including analyses of both Bergmann's and Allen's rules to investigate a functional connection between abiotic habitat conditions and the external morphology of the Middle East lacertid lizards; it also discusses the functional link between corporeal measurements and geographic variables. The findings are expected to contribute to our understanding of the potential importance of abiotic components as sources of morphological intraspecific 


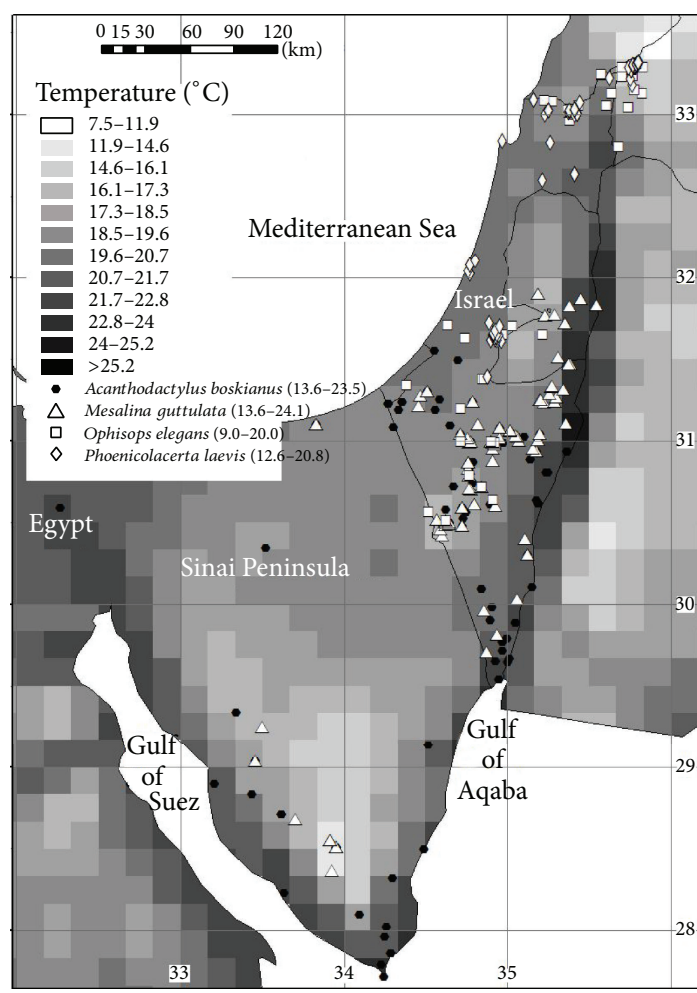

(a)

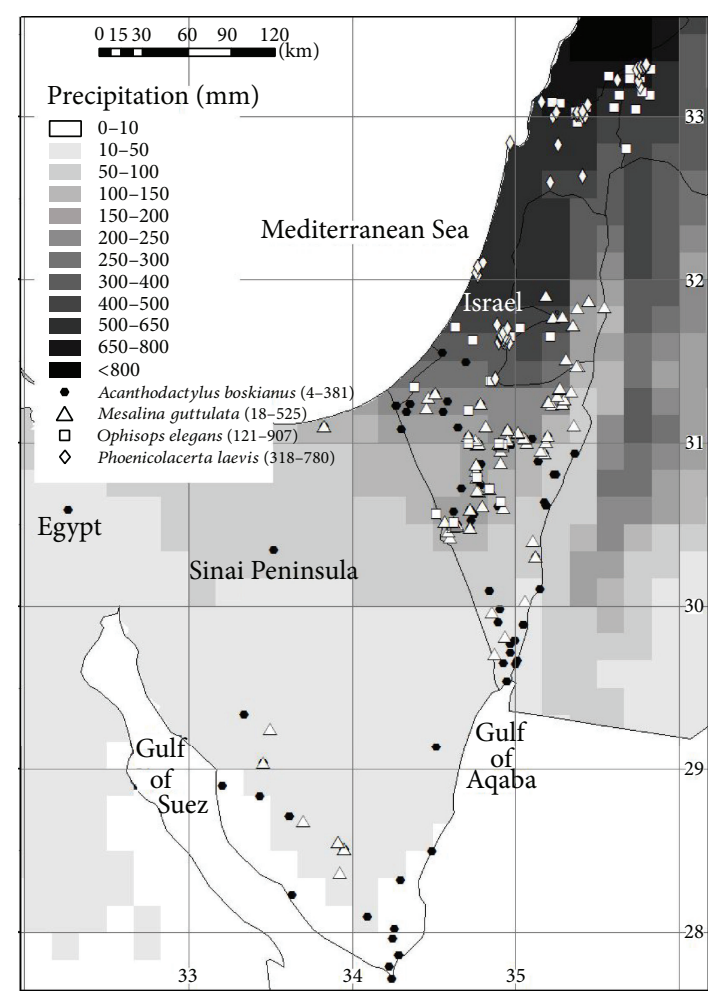

(b)

FIGURE 1: Climatic maps of the studied areas (excluding Turkish localities). (a) Average annual temperature and (b) average annual precipitation. The ranges of temperature and precipitation for each species are given in brackets.

variability in ectothermic vertebrates, whose metabolic rates and life history are greatly affected by environments.

\section{Material and Methods}

2.1. Samples and Site Locations. The observed specimens were adult males and females of four lizard species (more than 100 individuals per species), with large geographic ranges. I measured 679 preserved specimens of four lacertid species in the Natural History Museum of the Department of Zoology, Faculty of Life Sciences, Tel Aviv University (TAUM). The specimens had been collected between 1941 and 2012, mostly 86.6\% from Israel but some 71 from Egypt (the Sinai Peninsula) and 20 specimens from Turkey.

The following specimens were collected: Phoenicolacerta laevis, 104 specimens were collected from Mt. Hermon, the Golan Heights, the Galilee, the foothills of Judea, and the coastal plain (Israel); Ophisops elegans, 127 specimens were collected from Israel (Mt. Hermon, the Golan Heights, the Galilee, the Judean foothills, and the northern and central Negev) and 20 specimens from Turkey; Acanthodactylus boskianus, 164 specimens were collected from Israel (the A'rava Valley and the northern, central, and southern Negev) and 50 specimens from Egypt (northern Sinai, Sinai mountains, and the western Sinai coastal plain); Mesalina guttulata, 193 specimens were collected from Israel (the Judean Hills, the Judean Desert, Dead Sea area, and the northern, central, and southern Negev) and 21 specimens from Egypt (the northern Sinai and Sinai mountains).
2.2. Study Species. Phoenicolacerta laevis (Gray, 1838) is a medium-sized lizard, SVL up to $77 \mathrm{~mm}$ (according to our records), generally distributed in the Mediterranean landscape from Turkey to Israel and Jordan. This fairly adaptable species is found in relatively humid biotopes, such as temperate forests, valleys, Mediterranean-type shrub vegetation, cultivated fields, and gardens ([45, 46] pers. obs.). It is found from $200 \mathrm{~m}$ below sea level up to $2200 \mathrm{~m}$ above sea level (TAUM records).

Ophisops elegans (Ménétriés, 1832) is a small, slender lizard. The largest specimen in our sample has a SVL of $59 \mathrm{~mm}$. It occurs in open arid plains of the Mediterranean region and Central Asia and was found in sparse forests, vegetated rocky hillsides, and wadis [46-48]. Its vertical distribution ranges from $240 \mathrm{~m}$ below sea level to $2000 \mathrm{~m}$ above sea level (TAUM records).

Acanthodactylus boskianus (Daudin, 1802) is a mediumsized lizard, with adults up to $88 \mathrm{~mm}$ SVL. It is widespread in desert and semidesert areas of the Saharo-Arabian region from northern Africa through the eastern Mediterranean and the Arabian Peninsula to Iraq. It inhabits rather hard substrate and occupies a wide range of sandy and gravel habitats. It was collected from $400 \mathrm{~m}$ below sea level to $1300 \mathrm{~m}$ above sea level $[46,48,49]$.

Mesalina guttulata (Lichtenstein, 1823) is a rather small, slender lizard, with a maximum SVL of $57 \mathrm{~mm}$. It is widely distributed in North Africa and south-west Asia. It usually inhabits desert and semidesert regions with various terrains, 
prefers hard substrate and scattered rocks, and avoids sand dunes [46-48]. It is found from $350 \mathrm{~m}$ below sea level to $2000 \mathrm{~m}$ above sea level (TAUM records).

2.3. Morphological Measurements. For each specimen, I measured the following: snout-vent length (SVL); humerus length $(\mathrm{HmL})$, distance from axilla to apex of elbow; forearm length $(\mathrm{FaL})$, distance from elbow apex to apex of wrist; femur length $(\mathrm{FeL})$, distance from groin to apex of knee; and tibia length (TbL), distance from apex of knee to heel. From these, total fore limb length (FLL) and total hind limb length (HLL), which were obtained as the sums of the corresponding segment lengths (i.e., $\mathrm{HmL}+\mathrm{FaL}$ and $\mathrm{FeL}+\mathrm{TbL}$ ), as well as the limbs-body ratios (HmL/SVL, FaL/SVL, FeL/SVL, TbL/SVL) were calculated. Tail length was not included in the analysis because many individuals had broken or regenerated tails. For each specimen I also recorded collection data (region and locality with geographic coordinates and elevation), as well as body weight ( $M)$, which was taken shortly after capture to the nearest $0.1 \mathrm{~g}$. Sex was determined by tail base shape and hemipenis eversion or, in doubtful cases, by dissection. Measurements were made with a digital caliper (Mitutoyo CD-6" CX) to the nearest $0.01 \mathrm{~mm}$, except for SVL, which was measured to the nearest $0.5 \mathrm{~mm}$ using a millimeter ruler. I could not record all measurements from each specimen due to the bad preservation conditions of some reptiles, so the sample sizes vary among features (Table 1). All measurements were made by the author.

2.4. Meteorological Data. The climate elements considered were average annual temperature and average annual precipitation within the natural locations of the animals. Spatially interpolated climate data [50] for the 1950-2000 period, on grids with spatial resolution of 30 arc-second (often referred to as $1-\mathrm{km}$ spatial resolution), were taken from http://www .worldclim.org and imported into a GIS application.

2.5. Data Analyses. I applied one-way ANOVA with multiple testing corrections (Duncan's multiple range test, MRT) to examine the presence of sexual size dimorphism (SSD) in body and limb dimensions in all species studied. I used simple ordinary least squares (OLS) regression model, treating temperature and precipitation as continuous predictors, to assess the relationship between abiotic environmental components and morphological traits. In this analysis, the examined samples suppose a great dispersion of the data that cannot be addressed with log-transformations. In fact, both body size ranges within the samples and the sample sizes across the observed locations vary among the species. However, prior to analyses the data were tested for normality (ShapiroWilk's test) and homogeneity of variances (Levene's test). As argued in the Introduction, testing the possible presence of intraspecific clines requires that sexual size dimorphism within the species studied to be taken into account. In view of these considerations, relationships between abiotic variables and the measurements/ratios were tested for each sex separately. I also controlled for the effect of temperature and precipitation on limb length (for each sex separately) by MANCOVA using SVL as a covariate. In this analysis, both abiotic factors treated separately as categorical predictors and total fore limb length (FLL) and total hind limb length (HLL) as dependent variables. Multiple ordinary least squares (OLS) regression analysis, using SVL as a dependent variable and treating climatic factors as predictors, was applied to examine the combined effect of temperature and precipitation on body size. Here, in order to produce a more meaningful index of the observed effects, the slope coefficients were transformed into standardized "beta" coefficients $(\beta)$. All statistical analyses were done using Statistica 8 (StatSoft, Inc., USA).

\section{Results}

3.1. Sexual Dimorphism. Summary data of basic morphological features for males and females of each species are given in Table 1. Simple intersexual comparisons (one-way ANOVA) of the lizards' external morphology indicate that male $O$. elegans and $A$. boskianus are significantly $(P<0.0001)$ longer and heavier than females (Table 1). In M. guttulata females are longer but not heavier than males. In $P$. laevis males are marginally, nonsignificantly heavier than females but not longer.

Moreover, there is a pronounced sexual dimorphism $(P<$ $0.0001)$ in extremity length. Within all the species studied in absolute terms (mm) HmL, FaL, FeL, and TbL in males were much greater (from 7.3 to 13.6\%) than those in conspecific females. Assessing the ratios of fore and hind limbs' segments relative to SVL (i.e., HmL/SVL, FaL/SVL, FeL/SVL, and TbL/SVL) made very little difference (data not shown).

\subsection{Environment-Related Variation}

P. laevis. The studied locations are characterized by a highly significant correlation between latitude and both temperature $(r=-0.607, P<0.0001)$ and precipitation $(r=0.879$, $P<0.0001)$, and between temperature and precipitations as well $(r=-0.732, P<0.0001)$. Considering body size gradient, the scatter plots shown in Figure 2 indicate that although the individuals exhibit a notable dispersion (it is also true for other species studied) the major trends become evident. Male SVL does not vary significantly in relation to climate (temperature: OLS slope $\pm \mathrm{SE}=-0.25 \pm 0.45, r=$ $-0.081, P=0.585$; precipitation: slope $=-0.001 \pm 0.006$, $r=-0.032, P=0.827)$, whereas females are greatly affected by it, growing significantly heavier and longer (Figures 2(a) and $2(\mathrm{~b})$ ) in cool and wet habitats (temperature: slope $=$ $-1.47 \pm 0.31, r=-0.543, P<0.0001$; precipitation: slope $=$ $0.01 \pm 0.004, r=0.369, P=0.005)$. Continuous sampling (Table 2) revealed a stronger effect of climate on corporeal proportions than on absolute sizes. Analysis of latitudinal variability in body proportions showed a significant relationship between temperature and relative extremities length. In both sexes, relatively larger limbs are associated with hot habitats; among females, the recorded temperature-related correlation was highly significant for these morphological variables. The influence of precipitation was less obvious, although in females it was still significant for all ratios. In males, only $\mathrm{HmL} / \mathrm{SVL}$ varied in relation to precipitation. With SVL as a covariate, however, a MANCOVA indicates a 
TABLE 1: Morphological characteristics of lizard species studied and their intersexual comparisons (one-way ANOVA with multiple testing corrections; Duncan's multiple range test, MRT).

\begin{tabular}{|c|c|c|c|c|c|c|c|c|}
\hline \multirow{2}{*}{ Species } & \multirow{2}{*}{ Features } & \multicolumn{2}{|c|}{ Range } & \multicolumn{2}{|c|}{ Mean \pm SD } & \multirow{2}{*}{$\begin{array}{c}n \\
\text { ơ/우우 }\end{array}$} & \multirow{2}{*}{$P$} & \multirow{2}{*}{$F$} \\
\hline & & $0^{\hat{\alpha}}$ & 우 & 00 & 우우 & & & \\
\hline \multirow{6}{*}{$\begin{array}{l}\text { Phoenicolacerta } \\
\text { laevis }\end{array}$} & $M(\mathrm{~g})$ & $2.5-10.5$ & $3-11.4$ & $5.85 \pm 1.91$ & $5.13 \pm 1.94$ & $48 / 56$ & 0.059 & 3.62 \\
\hline & SVL (mm) & $50.5-77$ & $50-76$ & $63.53 \pm 6.65$ & $62.97 \pm 6.01$ & $48 / 56$ & 0.654 & 0.20 \\
\hline & $\mathrm{HmL}(\mathrm{mm})$ & 5.3-9 & $5.22-7.34$ & $6.99 \pm 0.79$ & $6.34 \pm 0.47$ & $47 / 56$ & 0.0001 & 26.36 \\
\hline & $\mathrm{FaL}(\mathrm{mm})$ & $5.9-9.32$ & $5.9-7.8$ & $7.61 \pm 0.77$ & $6.96 \pm 0.46$ & $47 / 56$ & 0.0001 & 28.49 \\
\hline & $\mathrm{FeL}(\mathrm{mm})$ & $7.62-11.84$ & $7.7-10.5$ & $9.66 \pm 1.03$ & $8.78 \pm 0.63$ & $47 / 56$ & 0.0001 & 27.40 \\
\hline & $\mathrm{TbL}(\mathrm{mm})$ & 8.75-13 & $8.5-11.4$ & $11.04 \pm 1.02$ & $9.87 \pm 0.62$ & $47 / 56$ & 0.0001 & 51.01 \\
\hline \multirow{6}{*}{ Ophisops elegans } & $M(\mathrm{~g})$ & $0.9-4.2$ & $1.2-3.5$ & $2.5 \pm 0.72$ & $1.98 \pm 0.51$ & $85 / 62$ & $<0.0001$ & 23.22 \\
\hline & SVL (mm) & $40-59$ & $40-53.5$ & $48.07 \pm 4.27$ & $46.47 \pm 3.44$ & $85 / 62$ & 0.016 & 5.85 \\
\hline & $\mathrm{HmL}(\mathrm{mm})$ & $4.45-6.1$ & $3.9-5.4$ & $5.3 \pm 0.4$ & $4.66 \pm 0.35$ & $84 / 61$ & $<0.0001$ & 98.38 \\
\hline & $\mathrm{FaL}(\mathrm{mm})$ & $4.78-6.72$ & $4.23-6.22$ & $5.82 \pm 0.5$ & $5.15 \pm 0.41$ & $84 / 61$ & $<0.0001$ & 73.20 \\
\hline & $\mathrm{FeL}(\mathrm{mm})$ & $5.3-8.72$ & $5.2-7.47$ & $7.22 \pm 0.71$ & $6.29 \pm 0.57$ & $84 / 61$ & $<0.0001$ & 69.11 \\
\hline & $\mathrm{TbL}(\mathrm{mm})$ & $7.15-10.53$ & $6.46-9.22$ & $9 \pm 0.81$ & $7.78 \pm 0.63$ & $84 / 61$ & $<0.0001$ & 95.38 \\
\hline \multirow{6}{*}{$\begin{array}{l}\text { Acanthodactylus } \\
\text { boskianus }\end{array}$} & $M(\mathrm{~g})$ & $1.7-13.8$ & $3-12.1$ & $6.99 \pm 2.15$ & $5.35 \pm 1.63$ & $121 / 93$ & $<0.0001$ & 37.23 \\
\hline & SVL (mm) & $52-88$ & $50-80.5$ & $65.9 \pm 6.46$ & $61.11 \pm 5.83$ & $121 / 93$ & $<0.0001$ & 31.31 \\
\hline & $\mathrm{HmL}(\mathrm{mm})$ & $5.2-9.18$ & $4.62-7.3$ & $6.9 \pm 0.75$ & $6.26 \pm 0.56$ & $113 / 85$ & $<0.0001$ & 43.33 \\
\hline & $\mathrm{FaL}(\mathrm{mm})$ & $5.92-9.92$ & $5.8-8.48$ & $7.96 \pm 0.79$ & $7.12 \pm 0.62$ & $113 / 85$ & $<0.0001$ & 65.57 \\
\hline & $\mathrm{FeL}(\mathrm{mm})$ & $8.45-13.38$ & $8.3-12.28$ & $11.2 \pm 1.04$ & $9.81 \pm 0.75$ & $114 / 85$ & $<0.0001$ & 108.62 \\
\hline & $\mathrm{TbL}(\mathrm{mm})$ & $10.8-16.4$ & $10-14.54$ & $13.77 \pm 1.19$ & $12.12 \pm 0.87$ & $114 / 85$ & $<0.0001$ & 116.06 \\
\hline \multirow{6}{*}{$\begin{array}{l}\text { Mesalina } \\
\text { guttulata }\end{array}$} & $M(\mathrm{~g})$ & $0.8-6$ & $1.16-3.7$ & $2.04 \pm 0.63$ & $2.01 \pm 0.56$ & $98 / 79$ & 0.748 & 0.10 \\
\hline & SVL (mm) & $40-57$ & $40-56$ & $45.61 \pm 3.01$ & $46.9 \pm 3.73$ & $119 / 95$ & 0.005 & 7.80 \\
\hline & $\mathrm{HmL}(\mathrm{mm})$ & $4.13-5.9$ & $3.9-5.4$ & $5 \pm 0.31$ & $4.62 \pm 0.29$ & $118 / 95$ & $<0.0001$ & 78.22 \\
\hline & $\mathrm{FaL}(\mathrm{mm})$ & $4.5-6.24$ & $4.2-5.6$ & $5.34 \pm 0.3$ & $4.95 \pm 0.3$ & $118 / 95$ & $<0.0001$ & 84.09 \\
\hline & $\mathrm{FeL}(\mathrm{mm})$ & $5.95-8.2$ & $5.57-7.76$ & $7.07 \pm 0.46$ & $6.52 \pm 0.41$ & $118 / 95$ & $<0.0001$ & 79.61 \\
\hline & $\mathrm{TbL}(\mathrm{mm})$ & $7.17-9.67$ & $6.64-8.8$ & $8.39 \pm 0.45$ & $7.63 \pm 0.44$ & $118 / 95$ & $<0.0001$ & 152.51 \\
\hline
\end{tabular}

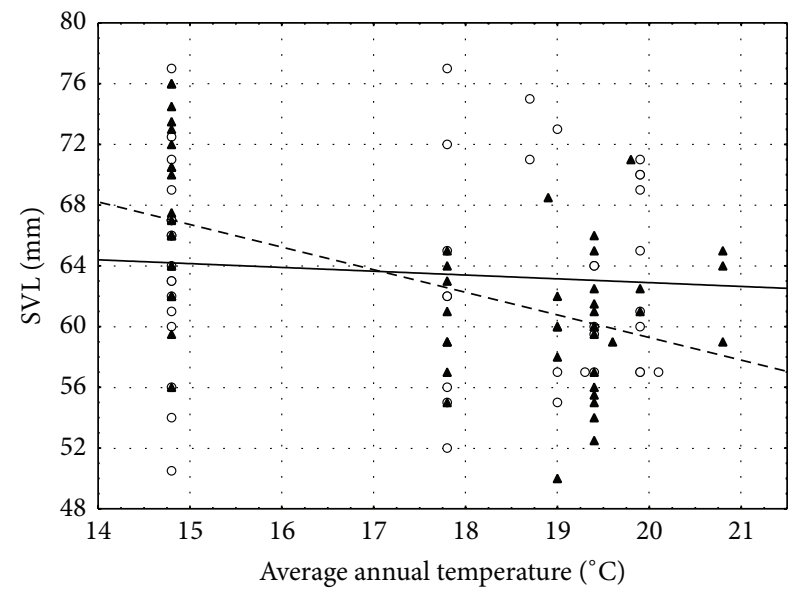

(a)

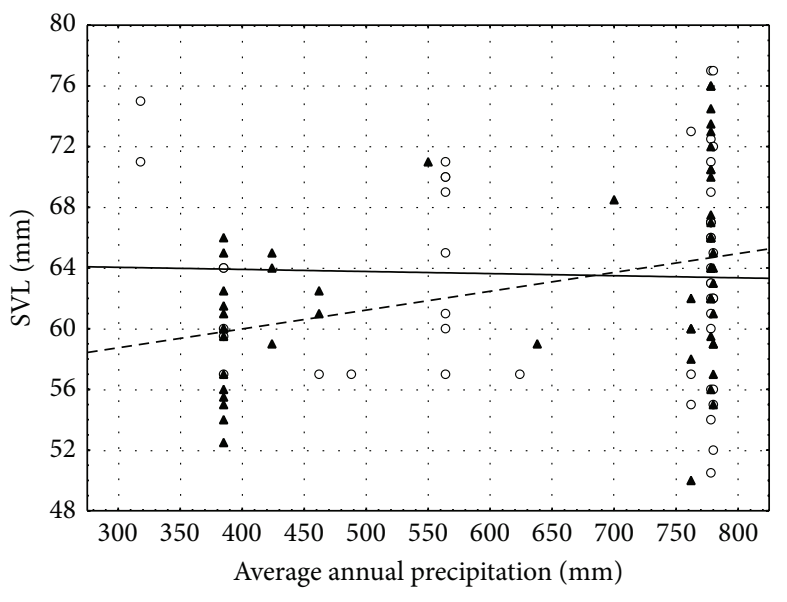

(b)

FIGURE 2: The relationship between SVL and (a) average annual temperature and (b) average annual precipitation in Phoenicolacerta laevis: solid line with circles: males; dashed line with triangles: females.

statistically significant effect of temperature on both FLL and HLL in females (Table 3). The results of multiple regression with SVL as a response (Table 4 ) indicate that the body sizeenvironment link is more obvious in respect to temperature than to precipitation. Thus, in females SVL is much more affected by the former variable: $P=0.0009, \beta=-0.61 \pm 0.17$, than by the latter: $P=0.588, \beta=-0.09 \pm 0.17$.

O. elegans. Examination of the environmental relationship across the observed area of this mostly Mediterranean species demonstrates a highly significant correlation between latitude and both temperature $(r=-0.801, P<0.0001)$ and precipitation $(r=0.433, P<0.0001)$. Temperature is negatively correlated with precipitation $(r=-0.388, P<0.0001)$. Snout-vent lengths (Figures 3(a) and 3(b)) of both sexes increase with temperature (males: slope $=-0.72 \pm 0.18, r=$ $-0.402, P=0.0001$; females: slope $=-0.49 \pm 0.14, r=-0.408$, $P=0.001$ ) and with precipitation (males: slope $=0.007 \pm$ $0.001, r=0.395, P=0.0002$; females: slope $=0.005 \pm 0.001$, $r=0.374, P=0.002)$. 
TABLE 2: Climate-morphology relationship between average annual temperature (AAT)/average annual precipitation (AAP) and body measurements/ratios (regression analysis with temperature and precipitation as the predictors and features as the responses). Positive correlation $(+)$ and negative correlation $(-)$; single sign: significant difference $(P<0.05)$ and double sign: highly significant difference $(P<$ 0.0001).

\begin{tabular}{|c|c|c|c|c|c|c|c|c|c|c|c|c|c|c|c|c|}
\hline \multirow{3}{*}{ Features } & \multicolumn{4}{|c|}{ Phoenicolacerta laevis } & \multicolumn{4}{|c|}{ Ophisops elegans } & \multicolumn{4}{|c|}{ Acanthodactylus boskianus } & \multicolumn{4}{|c|}{ Mesalina guttulata } \\
\hline & \multicolumn{2}{|c|}{ AAT } & \multicolumn{2}{|c|}{ AAP } & \multicolumn{2}{|c|}{ AAT } & \multicolumn{2}{|c|}{ AAP } & \multicolumn{2}{|c|}{ AAT } & \multicolumn{2}{|c|}{ AAP } & \multicolumn{2}{|c|}{ AAT } & \multicolumn{2}{|c|}{ AAP } \\
\hline & oto & 우 & ô & 우우 & oto & 우우 & $0^{\pi}$ & 우 & ôt & 우우 & $0^{*}$ & 우우 & oto & 우우 & $0^{*} 0^{*}$ & 우우 \\
\hline$M$ & & - & & + & - & & & + & & & & + & & & + & + \\
\hline SVL & & -- & & + & - & - & + & + & & - & & + & & & + & + \\
\hline $\mathrm{HmL}$ & & & & & - & - & + & ++ & & & & & & & & \\
\hline $\mathrm{FaL}$ & & & & & - & - & + & + & & & & & & & & + \\
\hline $\mathrm{FeL}$ & & & & & - & - & ++ & + & & & & & & & & \\
\hline $\mathrm{TbL}$ & & & & & - & - & + & + & & & & & & & & \\
\hline $\mathrm{HmL} / \mathrm{SVL}$ & + & ++ & - & - & + & & & & & & - & - & & + & & \\
\hline $\mathrm{FaL} / \mathrm{SVL}$ & + & ++ & & - & + & & & & & & -- & - & & + & & \\
\hline FeL/SVL & + & ++ & & -- & & & + & + & & + & - & - & & + & - & - \\
\hline TbL/SVL & + & ++ & & - & & & & & & + & - & - & & + & - & - \\
\hline
\end{tabular}

TABLE 3: Results of a MANCOVA examining the effect of temperature and precipitation on total fore limb length (FLL) and total hind limb length (HLL) in Phoenicolacerta laevis with SVL as a covariate. Significant effects are marked in bold letter.

\begin{tabular}{|c|c|c|c|c|c|c|c|c|c|}
\hline \multirow{2}{*}{$\begin{array}{l}\text { Source } \\
\text { of variation }\end{array}$} & \multirow{2}{*}{$\begin{array}{l}\text { Dependent } \\
\text { variable }\end{array}$} & \multicolumn{2}{|c|}{$\mathrm{df}$} & \multicolumn{2}{|c|}{ MS } & \multicolumn{2}{|c|}{$F$} & \multicolumn{2}{|c|}{$P$} \\
\hline & & 00 & 우우 & $\partial^{2} \sigma^{2}$ & 우 & $0^{2} \sigma^{\circ}$ & 우우 & 00 & 우우 \\
\hline \multirow{2}{*}{ Temperature } & FLL & 7 & 8 & 0.52 & 0.79 & 1.45 & 2.43 & 0.214 & 0.028 \\
\hline & HLL & 7 & 8 & 1.11 & 1.52 & 1.49 & 3.33 & 0.199 & 0.004 \\
\hline \multirow{2}{*}{$\begin{array}{l}\text { Covariate } \\
\text { (SVL) }\end{array}$} & FLL & 1 & 1 & 73.21 & 23.49 & 201.7 & 71.64 & $<0.001$ & $<0.001$ \\
\hline & HLL & 1 & 1 & 127.5 & 47.34 & 170.7 & 103.8 & $<0.001$ & $<0.001$ \\
\hline \multirow{2}{*}{ Factors } & FLL & 1 & 1 & 0.33 & 4.04 & 0.93 & 12.32 & 0.341 & $<0.001$ \\
\hline & HLL & 1 & 1 & 2.76 & 7.66 & 3.71 & 16.79 & 0.062 & $<0.001$ \\
\hline \multirow{2}{*}{ Error } & FLL & 37 & 46 & 0.36 & 0.33 & & & & \\
\hline & HLL & 37 & 46 & 0.74 & 0.45 & & & & \\
\hline \multirow{2}{*}{ Precipitation } & FLL & 8 & 8 & 0.47 & 0.64 & 1.26 & 1.87 & 0.294 & 0.088 \\
\hline & HLL & 8 & 8 & 0.99 & 1.50 & 1.30 & 3.27 & 0.275 & 0.005 \\
\hline \multirow{2}{*}{$\begin{array}{l}\text { Covariate } \\
\text { (SVL) }\end{array}$} & FLL & 1 & 1 & 71.08 & 21.62 & 191.3 & 62.75 & $<0.001$ & $<0.001$ \\
\hline & HLL & 1 & 1 & 120.8 & 46.77 & 158.2 & 101.7 & $<0.001$ & $<0.001$ \\
\hline \multirow{2}{*}{ Factors } & FLL & 1 & 1 & 0.30 & 4.93 & 0.81 & 14.33 & 0.374 & $<0.001$ \\
\hline & HLL & 1 & 1 & 2.96 & 7.98 & 3.88 & 17.38 & 0.056 & $<0.001$ \\
\hline \multirow{2}{*}{ Error } & FLL & 36 & 46 & 0.37 & 0.34 & & & & \\
\hline & HLL & 36 & 46 & 0.76 & 0.45 & & & & \\
\hline
\end{tabular}

TABLE 4: The effect of climate variables on snout-vent length (SVL). Results of multiple regression with SVL as a dependent variable and climatic factors as predictors.

\begin{tabular}{|c|c|c|c|c|c|c|c|}
\hline & & \multicolumn{3}{|c|}{ Effect of temperature } & \multicolumn{3}{|c|}{ Effect of precipitation } \\
\hline & & $\beta \pm \mathrm{SE}$ & $t$ & $P$ & $\beta \pm \mathrm{SE}$ & $t$ & $P$ \\
\hline \multirow{3}{*}{$\begin{array}{l}\text { Phoenicolacerta } \\
\text { laevis }\end{array}$} & 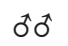 & $-0.21 \pm 0.21$ & -0.98 & 0.328 & $-0.18 \pm 0.21$ & -0.85 & 0.399 \\
\hline & 우 & $-0.615 \pm 0.17$ & -3.51 & 0.0009 & $-0.09 \pm 0.17$ & -0.54 & 0.588 \\
\hline & ôt & $-0.27 \pm 0.11$ & -2.51 & 0.013 & $0.26 \pm 0.11$ & 2.38 & 0.019 \\
\hline Ophisops elegans & 우 & $-0.32 \pm 0.12$ & -2.66 & 0.009 & $0.25 \pm 0.12$ & 2.08 & 0.041 \\
\hline \multirow{2}{*}{$\begin{array}{l}\text { Acanthodactylus } \\
\text { boskianus }\end{array}$} & ôे & $-0.03 \pm 0.09$ & -0.34 & 0.727 & $0.136 \pm 0.09$ & 1.37 & 0.207 \\
\hline & 우우 & $-0.13 \pm 0.11$ & -1.15 & 0.251 & $0.21 \pm 0.11$ & -1.77 & 0.079 \\
\hline \multirow{2}{*}{ Mesalina guttulata } & ơ & $-0.03 \pm 0.09$ & -0.41 & 0.68 & $0.21 \pm 0.09$ & 2.36 & 0.019 \\
\hline & 우우 & $-0.14 \pm 0.09$ & -1.51 & 0.134 & $0.33 \pm 0.09$ & 3.39 & 0.001 \\
\hline
\end{tabular}




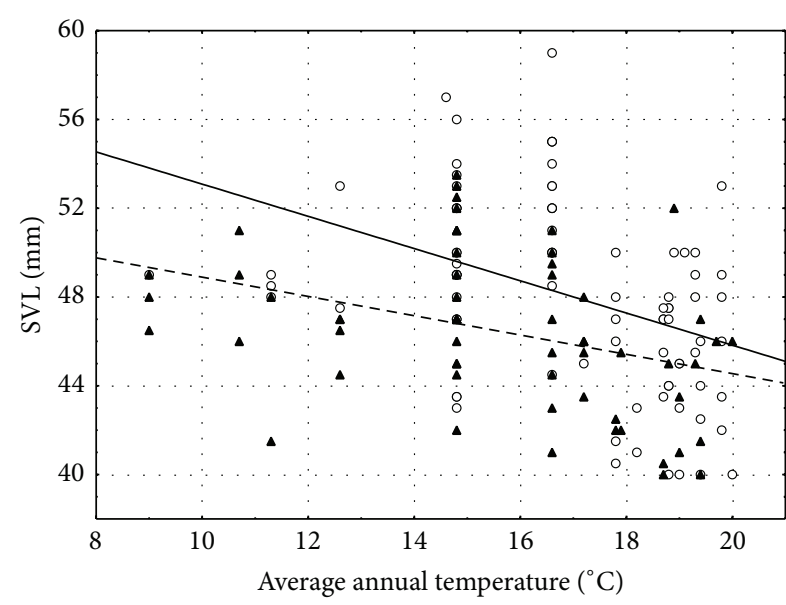

(a)

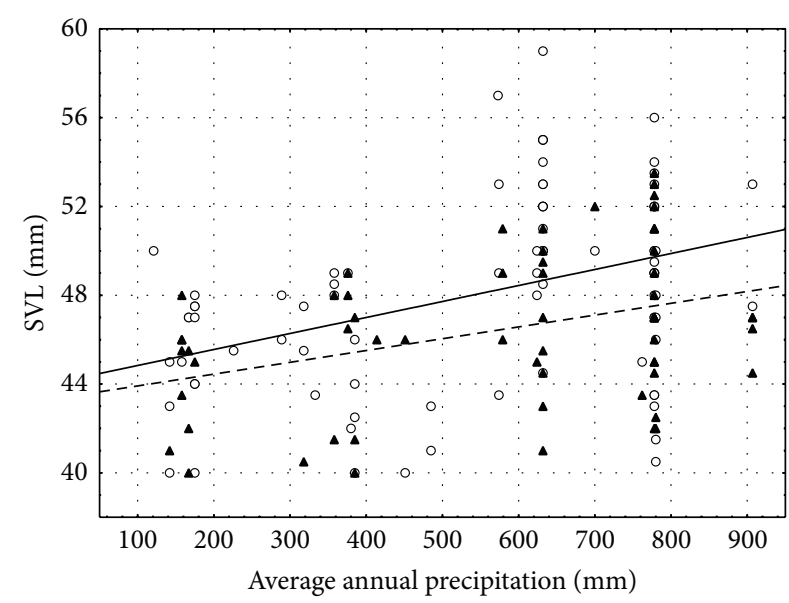

(b)

FIGURE 3: The relationship between SVL and (a) average annual temperature and (b) average annual precipitation in Ophisops elegans: solid line with circles: males; dashed line with triangles: females.

The corporeal ratios and, especially, lengths (Table 2) are noticeably influenced by the local climate conditions. Regression analysis indicates that the sexes generally follow similar trends in their corporal dimensions and become significantly larger at higher latitudes. By analogy with SVL, appendages were positively correlated with precipitation and were negatively correlated with temperature. In addition, in both sexes the longer femora may be associated with increased precipitation. However, after accounting for SVL, a MANCOVA reveals a nonsignificant effect of both abiotic predictors on limb size (Table 5). Multiple regression demonstrates the equivalency of two climate influences in their relationships with SVL (Table 4). Furthermore, males and females, in general, did not differ from one another in their responses to either temperature $(\beta=-0.27 \pm 0.11$ versus $\beta=-0.32 \pm 0.12)$ or precipitation $(\beta=0.26 \pm 0.11$ versus $\beta=0.25 \pm 0.12$ ) gradient.

A. boskianus. In the desert habitats of this species temperature was uncorrelated with latitude $(r=-0.082, P=0.247)$ across the observed geographic range. There is, however, a pronounced latitudinal precipitation gradient $(r=0.815$, $P<0.0001)$ and a negative relationship between annual averages of temperature and precipitation: $r=-0.367, P<$ 0.0001 . In this lizard, the sexes differ in respect to their environmental-morphological connection (Figures 4(a) and 4(b)). The SVL of males did not correlate consistently with temperature (slope $=-0.21 \pm 0.29, r=-0.067, P=0.485$ ) and precipitation (slope $=0.01 \pm 0.008, r=0.134, P=$ $0.160)$, whereas the SVL of females varied in relation to these variables: slope $=-0.81 \pm 0.34, r=-0.243, P=0.021$, and slope $=0.02 \pm 0.007, r=0.280, P=0.007$, for temperature and precipitation, respectively.

Corporeal measurements (Table 2) showed a close relationship with rainfall in both sexes and increased precipitation is correlated to shorter extremities relative to SVL. Despite the fact that the appendages tend to lengthen relative to their SVL with rise in temperature, this abiotic component would seem to affect only hind limb segments (FeL and TbL). The MANCOVA results (Table 6) also suggest that within both sexes, the temperature gradient significantly contributes only to HLL variation. Precipitation had a significant effect on hind extremity in both sexes; furthermore, within males it influenced the variation in FLL as well. Analysis of combined effect of environmental variables when both temperature and precipitation were regressed against SVL (Table 4) reveals the role of moisture as a major predictor of intraspecific variability. Moreover, males and females were similar in this trend: $\beta=-0.03 \pm 0.09$ (temperature), $\beta=0.136 \pm 0.09$ (precipitation) for males and $\beta=0.13 \pm 0.11$ versus $\beta=$ $0.21 \pm 0.11$ for females, respectively.

M. guttulata. The studied geographic range of this desert lacertid is characterized by a highly significant correlation between latitude and both temperature $(r=0.657, P<$ $0.0001)$ and precipitation $(r=0.682, P<0.0001)$, whereas temperature was uncorrelated with precipitation $(r=0.030$, $P=0.654$ ). In both sexes SVL (Figures 5(a) and 5(b)) increased along a rainfall gradient: slope $=0.006 \pm 0.002, r=$ $0.215, P=0.018$, for males; slope $=0.01 \pm 0.004, r=0.317$, $P=0.001$, for females. Continuous sampling also revealed an insignificant relationship between temperature and SVL in this species. Regression analysis (Table 2) indicated an important role of precipitation in the creation of clines in body and limb dimensions. Moreover, spatial changes of both climatic components may induce some allometric shifts in latitudinal space. Thus, temperature rise has led to the appearance of longer (relative to SVL) extremities among females. This observation was confirmed by MANCOVA; a significant association was observed between either FLL or HLLand temperature, as well as between HLL and precipitation. In males, this approach, however, indicates a nonsignificant effect of both climatic variables on limb dimensions (Table 7).

Similarly to other desert dwellers (A. boskianus), in this species too precipitation level is a stronger ecological determinant of body length (Table 4) than temperature gradient: 
TABLE 5: Results of a MANCOVA examining the effect of temperature and precipitation on total fore limb length (FLL) and total hind limb length (HLL) in Ophisops elegans with SVL as a covariate.

\begin{tabular}{|c|c|c|c|c|c|c|c|c|c|}
\hline \multirow{2}{*}{$\begin{array}{l}\text { Source } \\
\text { of variation }\end{array}$} & \multirow{2}{*}{$\begin{array}{l}\text { Dependent } \\
\text { variable }\end{array}$} & \multicolumn{2}{|c|}{$\mathrm{df}$} & \multicolumn{2}{|c|}{ MS } & \multicolumn{2}{|c|}{$F$} & \multicolumn{2}{|c|}{$P$} \\
\hline & & oto & 우우 & 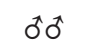 & 우우 & ôt & 우우 & $\sigma^{\top} \sigma^{2}$ & 우우 \\
\hline \multirow{2}{*}{ Temperature } & FLL & 17 & 16 & 0.12 & 0.26 & 0.81 & 1.40 & 0.672 & 0.186 \\
\hline & HLL & 17 & 16 & 0.48 & 0.71 & 1.21 & 1.47 & 0.278 & 0.155 \\
\hline \multirow{2}{*}{$\begin{array}{l}\text { Covariate } \\
\text { (SVL) }\end{array}$} & FLL & 1 & 1 & 25.22 & 5.29 & 163.3 & 28.64 & $<0.001$ & $<0.001$ \\
\hline & HLL & 1 & 1 & 56.96 & 15.25 & 143.2 & 31.83 & $<0.001$ & $<0.001$ \\
\hline \multirow{2}{*}{ Factors } & FLL & 1 & 1 & 1.01 & 2.51 & 6.51 & 13.59 & 0.013 & 0.001 \\
\hline & HLL & 1 & 1 & 1.38 & 2.65 & 3.47 & 5.52 & 0.067 & 0.023 \\
\hline \multirow{2}{*}{ Error } & FLL & 65 & 42 & 0.15 & 0.18 & & & & \\
\hline & HLL & 65 & 42 & 0.39 & 0.47 & & & & \\
\hline \multirow{2}{*}{ Precipitation } & FLL & 23 & 17 & 0.13 & 0.24 & 0.83 & 1.29 & 0.673 & 0.243 \\
\hline & HLL & 23 & 17 & 0.56 & 0.64 & 1.56 & 1.30 & 0.086 & 0.241 \\
\hline \multirow{2}{*}{$\begin{array}{l}\text { Covariate } \\
\text { (SVL) }\end{array}$} & FLL & 1 & 1 & 21.86 & 5.34 & 140.6 & 28.22 & $<0.001$ & $<0.001$ \\
\hline & HLL & 1 & 1 & 49.02 & 14.81 & 136.6 & 29.71 & $<0.001$ & $<0.001$ \\
\hline \multirow{2}{*}{ Factors } & FLL & 1 & 1 & 1.23 & 2.63 & 7.96 & 13.93 & 0.006 & 0.001 \\
\hline & HLL & 1 & 1 & 2.01 & 3.05 & 5.59 & 6.12 & 0.021 & 0.018 \\
\hline \multirow{2}{*}{ Error } & FLL & 59 & 41 & 0.15 & 0.18 & & & & \\
\hline & HLL & 59 & 41 & 0.35 & 0.49 & & & & \\
\hline
\end{tabular}

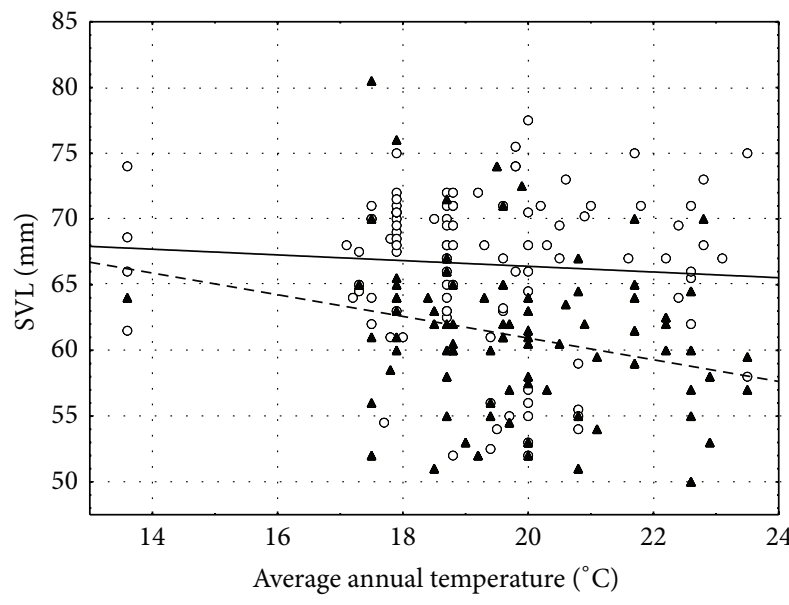

(a)

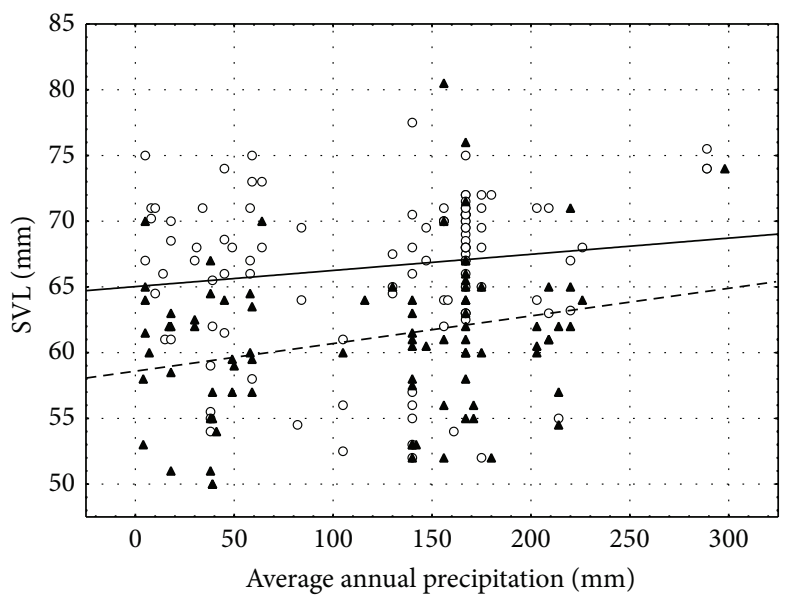

(b)

FIGURE 4: The relationship between SVL and (a) average annual temperature and (b) average annual precipitation in Acanthodactylus boskianus: solid line with circles: males; dashed line with triangles: females.

$P=0.019, \beta=0.21 \pm 0.09$, versus $P=0.680, \beta=-0.03 \pm 0.09$, for males; $P=0.001, \beta=0.33 \pm 0.09$, versus $P=0.134$, $\beta=-0.14 \pm 0.09$, for females, respectively.

\section{Discussion}

Despite the inability of ectotherms to produce significant metabolic heat, the interaction between body size and heat balance based on a set of behavioural, anatomical, and physiological mechanisms [51] that contribute to fitness might explain the peculiarity of ecological drivers in size clines among these animals. The relationship between habitat conditions and morphological variables (body, tail, or limb dimensions) and consequent shifts in phenology due to climate change have been observed across a wide range of reptile taxa [52-54]. It is possible that in diurnal squamates environmental conditions may favour selection for smallersized individuals [55] which, due to the ability to achieve more accurate adjustment of their body temperature, have better thermoregulatory capacities [56] and thus display high activity levels. In terrestrial ectotherms, thermoregulation is realized behaviourally by habitat selection and daily activity pattern [57], while at the same time, morphological specialization may also essentially facilitate it [55]. For example, Shine and Madsen [58] pointed out that for relatively small reptile species behavioural thermoregulation seems to be more important, especially in conditions of high diurnal thermal heterogeneity. In this context, desert reptiles inhabiting warmer regions with lower thermoregulatory costs may adjust their body temperature mainly behaviourally and, thus, invest less in adjustment of either body size or shape in relation to ambient temperature. Despite the great data 
TABLE 6: Results of a MANCOVA examining the effect of temperature and precipitation on total fore limb length (FLL) and total hind limb length (HLL) in Acanthodactylus boskianus with SVL as a covariate. Significant effects are marked in bold letter.

\begin{tabular}{|c|c|c|c|c|c|c|c|c|c|}
\hline \multirow{2}{*}{$\begin{array}{l}\text { Source } \\
\text { of variation }\end{array}$} & \multirow{2}{*}{$\begin{array}{l}\text { Dependent } \\
\text { variable }\end{array}$} & \multicolumn{2}{|c|}{$\mathrm{df}$} & \multicolumn{2}{|c|}{ MS } & \multicolumn{2}{|c|}{$F$} & \multicolumn{2}{|c|}{$P$} \\
\hline & & $00^{\pi}$ & 우우 & $0^{\pi}$ & 우우 & 00 & 우우 & $0^{\pi}$ & 우우 \\
\hline \multirow{2}{*}{ Temperature } & FLL & 35 & 28 & 0.89 & 0.53 & 1.41 & 1.25 & 0.118 & 0.239 \\
\hline & HLL & 35 & 28 & 1.51 & 1.31 & 1.91 & 1.75 & 0.012 & 0.040 \\
\hline \multirow{2}{*}{$\begin{array}{l}\text { Covariate } \\
\text { (SVL) }\end{array}$} & FLL & 1 & 1 & 60.44 & 34.36 & 95.26 & 80.18 & $<0.001$ & $<0.001$ \\
\hline & HLL & 1 & 1 & 173.1 & 61.25 & 218.6 & 81.76 & $<0.001$ & $<0.001$ \\
\hline \multirow{2}{*}{ Factors } & FLL & 1 & 1 & 2.03 & 4.95 & 3.20 & 11.56 & 0.078 & 0.001 \\
\hline & HLL & 1 & 1 & 4.45 & 29.11 & 5.62 & 38.85 & 0.021 & $<0.001$ \\
\hline \multirow{2}{*}{ Error } & FLL & 65 & 51 & 0.63 & 0.42 & & & & \\
\hline & HLL & 65 & 51 & 0.79 & 0.74 & & & & \\
\hline \multirow{2}{*}{ Precipitation } & FLL & 33 & 31 & 0.86 & 0.46 & 1.78 & 1.01 & 0.023 & 0.481 \\
\hline & HLL & 33 & 31 & 1.51 & 1.16 & 1.86 & 1.71 & 0.016 & 0.049 \\
\hline \multirow{2}{*}{$\begin{array}{l}\text { Covariate } \\
(\mathrm{SVL})\end{array}$} & FLL & 1 & 1 & 64.15 & 23.94 & 131.8 & 51.43 & $<0.001$ & $<0.001$ \\
\hline & HLL & 1 & 1 & 179.2 & 42.22 & 220.1 & 61.51 & $<0.001$ & $<0.001$ \\
\hline \multirow{2}{*}{ Factors } & FLL & 1 & 1 & 1.61 & 7.04 & 3.32 & 15.14 & 0.073 & $<0.001$ \\
\hline & HLL & 1 & 1 & 4.22 & 34.82 & 5.18 & 50.73 & 0.026 & $<0.001$ \\
\hline \multirow{2}{*}{ Error } & FLL & 67 & 48 & 0.48 & 0.46 & & & & \\
\hline & HLL & 67 & 48 & 0.81 & 0.68 & & & & \\
\hline
\end{tabular}

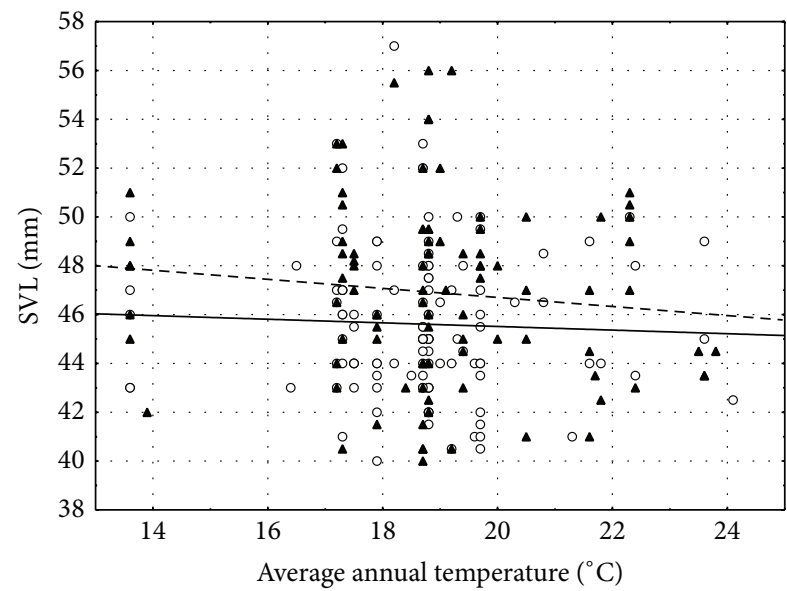

(a)

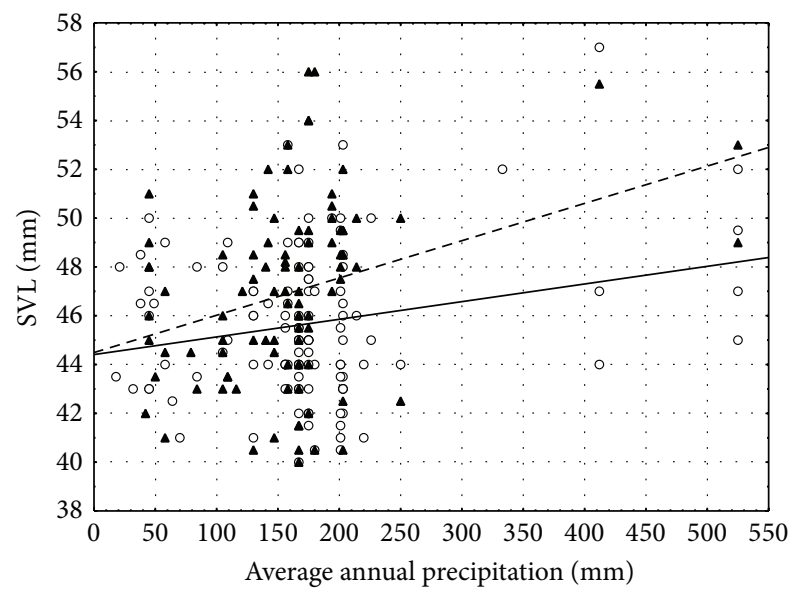

(b)

FIGURE 5: The relationship between SVL and (a) average annual temperature and (b) average annual precipitation in Mesalina guttulata: solid line with circles: males; dashed line with triangles: females.

dispersion (as shown in the scatter plots) it was found that among the two "desert" species studied (M. guttulata and $A$. boskianus) only females of the latter were smaller in hot temperatures, whereas in both sexes of the former, as well as in $A$. boskianus males, SVL did not correlate with temperature. In the Mediterranean region $P$. laevis and $O$. elegans inhabit cooler climates than the desert $A$. boskianus and M. guttulata. In these environments, larger gravid reptiles, in addition to the buffering effects of the behavioural thermoregulation supplied by the mother [59, 60], can provide greater temperature stability during the preoviposition period. Volynchik [19], however, found that a large-bodied local viper (Vipera palaestinae), with a Mediterranean distribution pattern, does not follow Bergmann's rule or its converse. At the same time, the most "cold-loving" lizard (O. elegans) in my own sample obeyed Bergmann's rule, growing larger in cooler environments. On the other hand, in desert habitats, this pattern of greater thermal inertia seems to be less important, and the behavioural component of thermoregulation becomes paramount.

The impact of ambient temperature on external morphology is also significant in respect to relative extremity lengths: different degrees of intraspecific variability in limb proportions supporting Allen's rule were observed in all the species studied. The present findings indicate that temperature decrease across the observed habitats could lead to reduction in size of extremity segments relative to body length, thus constituting a compensatory adaptation to either cooler or hotter areas. I noted an allometric shift in humerus, forearm, femur, and tibia lengths, relative to SVL, along a temperature gradient among P. laevis. A similar relationship between average annual temperature and corporeal ratios was 
TABLE 7: Results of a MANCOVA examining the effect of temperature and precipitation on total fore limb length (FLL) and total hind limb length (HLL) in Mesalina guttulata with SVL as a covariate. Significant effects are marked in bold letter.

\begin{tabular}{|c|c|c|c|c|c|c|c|c|c|}
\hline \multirow{2}{*}{$\begin{array}{l}\text { Source } \\
\text { of variation }\end{array}$} & \multirow{2}{*}{$\begin{array}{l}\text { Dependent } \\
\text { variable }\end{array}$} & \multicolumn{2}{|c|}{$\mathrm{df}$} & \multicolumn{2}{|c|}{ MS } & \multicolumn{2}{|c|}{$F$} & \multicolumn{2}{|c|}{$P$} \\
\hline & & 00 & 우우 & $0^{2} \sigma^{x}$ & 우우 & 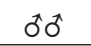 & 우우 & $\partial^{x} \sigma^{x}$ & 우우 \\
\hline \multirow{2}{*}{ Temperature } & FLL & 25 & 24 & 0.21 & 0.24 & 1.56 & 1.81 & 0.065 & 0.029 \\
\hline & HLL & 25 & 24 & 0.45 & 0.54 & 1.43 & 1.91 & 0.110 & 0.019 \\
\hline \multirow{2}{*}{$\begin{array}{l}\text { Covariate } \\
\text { (SVL) }\end{array}$} & FLL & 1 & 1 & 20.08 & 9.87 & 147.5 & 72.79 & $<0.001$ & $<0.001$ \\
\hline & HLL & 1 & 1 & 44.05 & 20.11 & 140.7 & 71.14 & $<0.001$ & $<0.001$ \\
\hline \multirow{2}{*}{ Factors } & FLL & 1 & 1 & 4.50 & 8.92 & 33.11 & 65.83 & $<0.001$ & $<0.001$ \\
\hline & HLL & 1 & 1 & 10.82 & 20.73 & 34.55 & 73.31 & $<0.001$ & $<0.001$ \\
\hline \multirow{2}{*}{ Error } & FLL & 91 & 69 & 0.13 & 0.13 & & & & \\
\hline & HLL & 91 & 69 & 0.31 & 0.28 & & & & \\
\hline \multirow{2}{*}{ Precipitation } & FLL & 28 & 25 & 0.19 & 0.22 & 1.42 & 1.62 & 0.107 & 0.059 \\
\hline & HLL & 28 & 25 & 0.41 & 0.56 & 1.29 & 2.11 & 0.181 & 0.008 \\
\hline \multirow{2}{*}{$\begin{array}{l}\text { Covariate } \\
(\mathrm{SVL})\end{array}$} & FLL & 1 & 1 & 19.50 & 9.63 & 140.9 & 68.66 & $<0.001$ & $<0.001$ \\
\hline & HLL & 1 & 1 & 41.81 & 19.08 & 130.7 & 70.94 & $<0.001$ & $<0.001$ \\
\hline \multirow{2}{*}{ Factors } & FLL & 1 & 1 & 3.56 & 8.02 & 25.75 & 57.17 & $<0.001$ & $<0.001$ \\
\hline & HLL & 1 & 1 & 9.01 & 19.18 & 28.17 & 71.33 & $<0.001$ & $<0.001$ \\
\hline \multirow{2}{*}{ Error } & FLL & 88 & 68 & 0.13 & 0.14 & & & & \\
\hline & HLL & 88 & 68 & 0.32 & 0.26 & & & & \\
\hline
\end{tabular}

noted in females of M. guttulata. Among A. boskianus total hind limb length significantly correlated with both thermal regime and rainfall gradient. Hence, both Mediterranean and desert reptiles follow a similar pattern in their body shape variation and may benefit from various morphological modifications matched to habitat range.

Body temperature changes affect reptile ecology [61], becoming more important to ectotherms living in cooler environments, which complicate attaining proper body temperature $[58,62]$. In support of this, my results show the association between biogeographic origins of the species examined and their relationship with environmental variables. On interspecific comparison, the most pronounced distinctions were noted in phenotypic responses to the temperature gradient between Mediterranean and desert inhabitants, while the between-species differences for precipitation-related variation were weaker. As expected, both Mediterranean region species ( $P$. laevis, O. elegans) display significantly stronger responses to temperature than desert dwellers (A. boskianus, M. guttulata). Apparently, the cooler locations of the former force them to exhibit more consistent morphological variability in respect to temperature changes, whereas for desert species such habitat-morphology connection seems to be less important. It is highly likely that the species' sensitivity to the environment is associated not only with their ecological differentiation, but also with body size ranges within the sample. Thus, this might be one possible explanation for the different, albeit relatively minor, responses to temperature between ecologically similar species (i.e., P. laevis versus $O$. elegans and A. boskianus versus $M$. guttulata) that were noted here. In the examined samples, L. laevis, owing to its greater measurement ranges than $O$. elegans, has a higher potential for more consistent matching of its body dimensions to the observed temperature gradient. The same is true for the two desert lizards; $A$. boskianus due to its extended body and limb ranges, in comparison with $M$. guttulata, displays a stronger morphological-environmental link.

The examination of gender-specific habitat-morphology interactions revealed that within three of the four species $(P$. laevis, A. boskianus, and M. guttulata) sensitivity to the environment is coupled with sex. Considering the effect of climate variables on SVL, the findings demonstrate that females, in general, show a more consistent link between temperature and body/limb measurements than males, while the effect of precipitation on external characters was similar for both sexes. Moreover, in $P$. laevis SVL was significantly more strongly correlated with the temperature gradient in females than in males. These observations indicate the sex-associated effect of natural selection, pointing to different thermal and metabolic demands in males and females. Thus, it is likely that in females the increased body size in colder environments is associated with reproduction-induced requirements. This pattern suggests that females, due to increased thermal requirements, particularly during vitellogenesis [63], are more able to generate a range of suitable morphological modifications for maintenance of optimal body temperature in local environments. Overall, my findings indicate that although females show a more consistent correlation between SVL and a temperature gradient than males, the body shape changes, involving both body and limb dimensions, are rather preliminary in explaining the observed intersexual divergence in the habitat-morphology relationship.

Environmental conditions within the nest experienced during early ontogenesis, especially temperature and moisture of substrate, can significantly affect development and growth trajectories of individuals in oviparous reptiles [6468]. As observed in many species, either posthatching phenotype or offspring fitness are closely associated with thermal regime $[63,69-71]$. In both the laboratory and in natural nests [64] temperature is traditionally considered to be an important environmental determinant of reptile size, while 
the effect of water-related factors is more complex. Several recent studies have tested the effect of substrate moisture during incubation of eggs on a diverse range of reptile species. Significant effects are found in certain species $[66,68,72,73]$ but not in others [74-76] that may reflect either different water permeability of the eggshell or interspecific variation in the water content of eggs [77]. On the other hand, the appearance of morphological variation along a precipitation gradient, which, in desert lizards, is even more evident than the temperature-related variability, can be considered as a response to the local habitats. In reptiles, food availability strongly affects growth trajectories and is one of the possible determinants of body size and shape [78-80]. Overall, in arid regions, where vegetation and arthropod fauna are determined primarily by precipitation [11], wetter localities provide better food resources to lizards at the population level. The present findings suggest that among desert species the possible spatial differences in prey availability and, thus, in nutrition levels, may lead to morphometric differentiation between specimens inhabiting dry or wet sites. However, detailed studies on possible dietary variation linked to local environments are necessary to answer the question of whether the habitat conditions, which are dependent on precipitation, have an effect on body dimensions in these lizards.

A nonphylogenetic approach suggests that lizard species tend to exhibit strong morphological specialization in relation to their habitat $[53,81]$. Variation in body characters related to locomotion which, in turn, is associated with substrate pattern, has been observed across many lizard taxa [54, 82-84]. Unfortunately, based on available datasets, I could not evaluate whether the shift in substrate usage is associated with limb proportion changes, and so a rational explanation for the effect of vegetation on limb lengths, through its dependence upon hydrothermal regime, remains to be determined. My findings show that, generally, the examined species indicate a uniform pattern in extremities size variation; fore and, especially, hind limb lengths were positively correlated with temperature and negatively with precipitation. The results indicate that ecological adaptation to abiotic factors is a powerful source of extremity size variation, which is under the effect of natural selection. In lizards, the morphology-performance relationships suggest that ground-dwelling species from open landscapes should possess relatively long limb segments to their body length [53]. This body shape pattern increases stride length providing better sprinting abilities $[85,86]$. Furthermore, shorter extremities may facilitate the locomotion in highly vegetated areas, where long limbs may be disadvantageous [53]. In this context, my findings suggest that various body shape patterns, such as relatively short/long limbs or their segments, which are suited to the environmental requirements, may reflect an adaptation to either dense or sparse vegetation, resulting from different rainfall intensities across the distribution range.

Finally, given the potential importance of habitats for limb size variation, lizards may also use their protruding body parts as additional (together with body surface area) heat exchangers. In these reptiles, for optimal balance between heat gain and heat loss, isometric size changes, to a certain extent, are a "two-edged sword," in which high thermal inertia of large bodies is accompanied by slow heating rates, and vice versa. In this respect, among desert dwellers relatively long extremities and small size enhance heat exchange and seem to be a morphological adaptation for effective thermoregulation. In desert areas, large daily fluctuations of temperature force the ectotherms to quickly respond to changing conditions and rapidly reach the necessary metabolic rates for locomotor activity. Long-limbed individuals which have an increased surface area-to-volume ratio may enhance their heating and cooling abilities through more effective interactions between the body and either solar radiation or surface temperature gradient. Hence, a consistent link between environmental variables and limb lengths can also be explained by their importance for maintenance of optimal body temperature in local environments. As shown above, the fact that the extremity size-environment link is more obvious in respect to hind limbs than to fore ones reinforces this hypothesis; relatively large hind limbs having an increased heat exchange capacity are much more powerful tool for effective thermoregulation than small fore extremities.

In summary, the lacertid lizards I studied generally followed the ecogeographic rules of Bergmann and Allen. In addition, the findings indicate both intersexual and interspecific differences in the habitat-morphology relationship, which can be considered within the framework of their functional connection. My data provide evidence that females tend to show stronger relationships between climate variables and body dimensions than males. In desert species temperature has a smaller effect than rainfall on lizard phenotypes. Under a constant dry climate, water availability seems to be the most important abiotic factor in reptile ecology. In this respect, due to the strong association between precipitation and productivity, my findings could also be interpreted as evidence for the hypothesis that different body size patterns are linked to the spatial variation in primary production, that is, the "resource rule." In the Mediterranean region lizards the thermal regime is apparently the main driving force of morphological variability. The present study suggests a complex link between environmental variables and morphological characters within lacertid species. The physical conditions, such as temperature and precipitation gradient, were shown to be able to significantly affect both body and limb dimensions, and, thus, as a powerful source of variation, they play an important role in lizard morphology. However, general statements about the habitatmorphology relationships and their potential importance for maintenance of optimal body temperature in reptiles are hard to make due to the enormous diversity of variations in body composition and physiology across species, sexes, and even individuals and the difficulty in evaluating enough mechanisms in enough species. Consequently, additional field and experimental studies testing both body size and shape variations and their relationships with environmental variables, especially at the intraspecific level and accounting for sex-specific aspects are needed to help determine whether the observed patterns are common across species and to what extent they are important for effective thermoregulation. 


\section{Conflict of Interests}

The author declares that there is no conflict of interests regarding the publication of this paper.

\section{Acknowledgments}

The author would like to thank Shai Meiri for his helpful comments on earlier drafts of the paper. The author thanks Erez Maza for assistance with data preparation, Anat Feldman for provision of the GIS-compatible temperature data, and Naomi Paz for linguistic editing. The author also thanks the Israel Ministry of Science, Culture and Sport for supporting the National Collections of Natural History at Tel Aviv University as a biodiversity, environment, and agriculture research knowledge centre.

\section{References}

[1] E. Mayr, Animal Species and Evolution, Harvard University Press, Cambridge, Mass, USA, 1963.

[2] C. Ray, "The application of Bergmann's and Allen's rules to the poikilotherms," Journal of Morphology, vol. 106, pp. 85-108, 1960.

[3] T. M. Blackburn, K. J. Gaston, and N. Loder, "Geographic gradients in body size: a clarification of Bergmann's rule," Diversity and Distributions, vol. 5, no. 4, pp. 165-174, 1999.

[4] K. J. Gaston and T. M. Blackburn, Pattern and Process in Macroecology, Blackwell, Malden, Mass, USA, 2000.

[5] C. Bergmann, "Über die verhältnisse der wärmeökonomie der thiere zu ihrer grösse," Gottinger Studien, vol. 3, pp. 595-708, 1847.

[6] J. A. Allen, "The influence of physical conditions in the genesis of species," Radical Review, vol. 1, pp. 108-140, 1877.

[7] F. C. James, "Geographic size variation in birds and its relationship with climate," Ecology, vol. 51, pp. 365-390, 1970.

[8] C. D. Burnett, "Geographic and climatic correlates of morphological variation in Eptesicus fuscus," Journal of Mammalogy, vol. 64, no. 3, pp. 437-444, 1983.

[9] C. C. Lindsey, "Body sizes of poikilotherm vertebrates at different latitudes," Evolution, vol. 20, pp. 456-465, 1966.

[10] M. L. Rosenzweig, "The strategy of body size in mammalian carnivores," American Midland Naturalist, vol. 80, pp. 299-315, 1968.

[11] Y. Yom-Tov and E. Geffen, "Geographic variation in body size: the effects of ambient temperature and precipitation," Oecologia, vol. 148, no. 2, pp. 213-218, 2006.

[12] Y. Yom-Tov and H. Nix, "Climatological correlates for body size of five species of Australian mammals," Biological Journal of the Linnean Society, vol. 29, no. 4, pp. 245-262, 1986.

[13] D. Pincheira-Donoso and S. Meiri, "An intercontinental analysis of climate-driven body size clines in reptiles: no support for patterns, no signals of processes," Evolutionary Biology, vol. 40, no. 4, pp. 562-578, 2013.

[14] K. G. Ashton, M. C. Tracy, and A. de Queiroz, "Is Bergmann's rule valid for mammals?” The American Naturalist, vol. 156, no. 4, pp. 390-415, 2000.

[15] S. Meiri and T. Dayan, "On the validity of Bergmann's rule," Journal of Biogeography, vol. 30, no. 3, pp. 331-351, 2003.
[16] K. G. Ashton, "Sensitivity of intraspecific latitudinal clines of body size for tetrapods to sampling, latitude and body size," Integrative and Comparative Biology, vol. 44, no. 6, pp. 403-412, 2004.

[17] K. G. Ashton and C. R. Feldman, "Bergmann's rule in nonavian reptiles: turtles follow it, lizards and snakes reverse it," Evolution, vol. 57, no. 5, pp. 1151-1163, 2003.

[18] M. Á. Olalla-Tárraga, M. Á. Rodríguez, and B. A. Hawkins, "Broad-scale patterns of body size in squamate reptiles of Europe and North America," Journal of Biogeography, vol. 33, no. 5, pp. 781-793, 2006.

[19] S. Volynchik, "Morphological variability in Vipera palaestinae along an environmental gradient," Asian Herpetological Research, vol. 3, pp. 227-239, 2012.

[20] D. Pincheira-Donoso, D. J. Hodgson, and T. Tregenza, "The evolution of body size under environmental gradients in ectotherms: why should Bergmann's rule apply to lizards?" BMC Evolutionary Biology, vol. 8, no. 1, article 68, 2008.

[21] R. C. Stillwell, "Are latitudinal clines in body size adaptive?" Oikos, vol. 119, no. 9, pp. 1387-1390, 2010.

[22] S. Meiri, "Bergmann's rule-what's in a name?" Global Ecology and Biogeography, vol. 20, no. 1, pp. 203-207, 2011.

[23] D. Pincheira-Donoso, "Predictable variation of range-sizes across an extreme environmental gradient in a lizard adaptive radiation: evolutionary and ecological inferences," PLOS ONE, vol. 6, no. 12, Article ID e28942, 2011.

[24] K. G. Ashton, “Do amphibians follow Bergmann's rule?” Canadian Journal of Zoology, vol. 80, no. 4, pp. 708-716, 2002.

[25] M. J. Angilletta Jr., T. D. Steury, and M. W. Sears, “Temperature, growth rate, and body size in ectotherms: fitting pieces of a lifehistory puzzle," Integrative and Comparative Biology, vol. 44, no. 6, pp. 498-509, 2004.

[26] C. E. Oufiero, G. E. A. Gartner, S. C. Adolph, and T. Garland, "Latitudinal and climatic variation in body size and dorsal scale counts in Sceloporus lizards: a phylogenetic perspective," Evolution, vol. 65, no. 12, pp. 3590-3607, 2011.

[27] S. Meiri, "Evolution and ecology of lizard body sizes," Global Ecology and Biogeography, vol. 17, no. 6, pp. 724-734, 2008.

[28] D. Atkinson and R. M. Sibly, "Why are organisms usually bigger in colder environments? Making sense of a life history puzzle," Trends in Ecology \& Evolution, vol. 12, pp. 235-239, 1997.

[29] F. B. Cruz, L. A. Fitzgerald, R. E. Espinoza, and J. A. Schulte II, "The importance of phylogenetic scale in tests of Bergmann's and Rapoport's rules: lessons from a clade of South American lizards," Journal of Evolutionary Biology, vol. 18, no. 6, pp. 15591574, 2005.

[30] T. A. Mousseau, "Ectotherms follow the converse to Bergmann's Rule," Evolution, vol. 51, pp. 630-632, 1997.

[31] R. N. Reed, "Interspecific patterns of species richness, geographic range size, and body size among New World venomous snakes," Ecography, vol. 26, no. 1, pp. 107-117, 2003.

[32] D. Pincheira-Donoso, T. Tregenza, and D. J. Hodgson, "Body size evolution in South American Liolaemus lizards of the boulengeri clade: a contrasting reassessment," Journal of Evolutionary Biology, vol. 20, no. 5, pp. 2067-2071, 2007.

[33] M. J. Angilletta, P. H. Niewiarowski, A. E. Dunham, A. Leaché, and W. P. Porter, "Bergmann's clines in ectotherms: illustrating a life-historical perspective with sceloporine lizards," The American Naturalist, vol. 164, pp. E168-E183, 2004.

[34] M. Andersson, Sexual Selection, Princeton University Press, Princeton, NJ, USA, 1994. 
[35] F. Braña, "Sexual dimorphism in lacertid lizards: male head increase vs. female abdomen increase?” Oikos, vol. 75, pp. 511$523,1996$.

[36] E. R. Pianka, "Lizard species density in the Kalahari desert," Ecology, vol. 52, pp. 1024-1029, 1971.

[37] E. R. Pianka, "Some intercontinental comparisons of desert lizards," National Geographic Research, vol. 1, no. 4, pp. 490-504, 1985.

[38] B. H. Brattstrom, "Social and thermoregulatory behavior of the bearded dragon, Amphibolurus barbatus," Copeia, vol. 3, pp. 484-497, 1971.

[39] G. C. Grigg and F. Seebacher, "Field test of a paradigm: hysteresis of heart rate in thermoregulation by a free-ranging lizard (Pogona barbata)," Proceedings of the Royal Society B: Biological Sciences, vol. 266, no. 1425, pp. 1291-1297, 1999.

[40] F. Seebacher and C. E. Franklin, "Control of heart rate during thermoregulation in the heliothermic lizard Pogona barbata: importance of cholinergic and adrenergic mechanisms," The Journal of Experimental Biology, vol. 204, no. 24, pp. 4361-4366, 2001.

[41] G. J. Tattersall and R. M. Gerlach, "Hypoxia progressively lowers thermal gaping thresholds in bearded dragons, Pogona vitticeps," The Journal of Experimental Biology, vol. 208, no. 17, pp. 3321-3330, 2005.

[42] D. F. DeNardo, T. E. Zubal, and T. C. M. Hoffman, "Cloacal evaporative cooling: a previously undescribed means of increasing evaporative water loss at higher temperatures in a desert ectotherm, the Gila monster Heloderma suspectum," The Journal of Experimental Biology, vol. 207, no. 6, pp. 945-953, 2004.

[43] S. Jaffe, "Climate of Israel," in The Zoogeography of Israel, Y. YomTov and E. Tchernov, Eds., pp. 79-92, Dr W. Junk Publishers, Dordrecht, The Netherlands, 1988.

[44] U. Roll, L. Stone, and S. Meiri, "Hot-spot facts and artifactsquestioning Israel's great biodiversity," Israel Journal of Ecology and Evolution, vol. 55, no. 3, pp. 263-279, 2009.

[45] W. Bischoff and J. F. Schmidtler, "New data on the distribution, morphology and habitat choice of the Lacerta laevis-kulzeri complex," Natura Croatica, vol. 8, no. 3, pp. 211-222, 1999.

[46] A. Disi, D. Modrý, P. Nečas, and L. Rifai, Amphibians and Reptiles of the Hashemite Kingdom of Jordan. An Atlas and Field Guide, Edit Chimaira, Frankfurt, Germany, 2001.

[47] A. Bouskila and P. Amitai, Handbook of Amphibians and Reptiles of Israel, Keter Publishing House, Jerusalem, Israel, 2001, (Hebrew).

[48] A. Bar and G. Haimovitch, A Field Guide to Reptiles and Amphibians of Israel, Pazbar LTD, Herzliya, Israel, 2012.

[49] Y. L. Werner, "Geographic sympatry of Acanthodactylus opheodurus with A. boskianus in the Levant," Zoology in the Middle East, vol. 1, pp. 92-95, 1986.

[50] R. J. Hijmans, S. E. Cameron, J. L. Parra, P. G. Jones, and A. Jarvis, "Very high resolution interpolated climate surfaces for global land areas," International Journal of Climatology, vol. 25, no. 15, pp. 1965-1978, 2005.

[51] R. B. Huey, "Temperature, physiology, and the ecology of reptiles," in Biology of the Reptilia, C. Gans and F. H. Pough, Eds., vol. 12 of Physiology (C), pp. 25-91, Academic Press, New York, NY, USA, 1982.

[52] D. J. Irschick and J. B. Losos, "Do lizards avoid habitats in which performance is submaximal? The relationship between sprinting capabilities and structural habitat use in Caribbean anoles," The American Naturalist, vol. 154, no. 3, pp. 293-305, 1999.
[53] B. Vanhooydonck and R. Van Damme, "Evolutionary relationships between body shape and habitat use in lacertid lizards," Evolutionary Ecology Research, vol. 1, no. 7, pp. 785-805, 1999.

[54] J. Melville and R. Swain, "Evolutionary relationships between morphology, performance and habitat openness in the lizard genus Niveoscincus (Scincidae: Lygosominae)," Biological Journal of the Linnean Society, vol. 70, no. 4, pp. 667-683, 2000.

[55] R. B. Huey and M. Slatkin, "Cost and benefits of lizard thermoregulation," The Quarterly Review of Biology, vol. 51, no. 3, pp. 363-384, 1976.

[56] R. D. Stevenson, "Body size and limits to the daily range of body temperature in terrestrial ectotherms," The American Naturalist, vol. 125, pp. 102-117, 1985.

[57] B. W. Grant, "Trade-offs in activity time and physiological performance for thermoregulating desert lizards, Sceloporus merriami," Ecology, vol. 71, no. 6, pp. 2323-2333, 1990.

[58] R. Shine and T. Madsen, "Is thermoregulation unimportant to most reptiles? An example using water pythons (Liasis fuscus) in tropical Australia," Physiological Zoology, vol. 69, pp. 252-269, 1996.

[59] R. Shine, "Reptilian viviparity in cold climates: testing the assumptions of an evolutionary hypothesis," Oecologia, vol. 57, no. 3, pp. 397-405, 1983.

[60] C. R. Peterson, A. R. Gibson, and M. E. Dorcas, "Snake thermal ecology: the causes and consequences of body temperature variation," in Snakes: Ecology and Behavior, R. A. Seigel and J. T. Collins, Eds., pp. 241-314, McGraw-Hill, New York, NY, USA, 1993.

[61] R. B. Huey and J. G. Kingsolver, "Evolution of thermal sensitivity of ectotherm performance," Trends in Ecology and Evolution, vol. 4, no. 5, pp. 131-135, 1989.

[62] J. A. Díaz, D. Bauwens, and B. Asensio, "A comparative study of the relation between heating rates and ambient temperatures in lacertid lizards," Physiological Zoology, vol. 69, pp. 1359-1383, 1996.

[63] D. C. Deeming, "Post-hatching phenotypic effects of incubation in reptiles," in Reptilian Incubation: Environment, Evolution and Behaviour, D. C. Deeming, Ed., pp. 229-251, Nottingham University Press, Nottingham, UK, 2004.

[64] R. Shine, M. J. Elphick, and P. S. Harlow, "The influence of natural incubation environments on the phenotypic traits of hatchling lizard," Ecology, vol. 78, pp. 2559-2568, 1997.

[65] T. Flatt, R. Shine, P. A. Borges-Landaez, and S. J. Downes, "Phenotypic variation in an oviparous montane lizard (Bassiana duperreyi): the effects of thermal and hydric incubation environments," Biological Journal of the Linnean Society, vol. 74, no. 3, pp. 339-350, 2001.

[66] R. Shine and M. J. Elphick, "The effect of short-term weather fluctuations on temperatures inside lizard nests, and on the phenotypic traits of hatchling lizards," Biological Journal of the Linnean Society, vol. 72, no. 4, pp. 555-565, 2001.

[67] O. Lourdais, R. Shine, X. Bonnet, M. Guillon, and G. Naulleau, "Climate affects embryonic development in a viviparous snake, Vipera aspis," Oikos, vol. 104, no. 3, pp. 551-560, 2004.

[68] V. Delmas, X. Bonnet, M. Girondot, and A.-C. Prévot-Julliard, "Varying hydric conditions during incubation influence egg water exchange and hatchling phenotype in the red-eared slider turtle," Physiological and Biochemical Zoology, vol. 81, no. 3, pp. 345-355, 2008.

[69] X.-F. Yan, X.-L. Tang, F. Yue et al., "Influence of ambient temperature on maternal thermoregulation and neonate phenotypes in 
a viviparous lizard, Eremias multiocellata, during the gestation period," Journal of Thermal Biology, vol. 36, no. 3, pp. 187-192, 2011.

[70] G. C. Packard and M. J. Packard, "The physiological ecology of reptilian eggs and embryos," in Biology of the Reptilia, C. Gans and R. B. Huey, Eds., vol. 16, pp. 525-605, Alan Liss, New York, NY, USA, 1988.

[71] D. C. Deeming and M. W. Ferguson, "Physiological effects of incubation temperature on embryonic development in reptiles and birds," in Egg Incubation: Its Effects on Embryonic Development in Birds and Reptiles, D. C. Deeming and M. W. J. Ferguson, Eds., pp. 147-171, Cambridge University Press, Cambridge, UK, 1991.

[72] B. Zhao, Y. Chen, Y. Wang, P. Ding, and W. G. Du, "Does the hydric environment affect the incubation of small rigid-shelled turtle eggs?" Comparative Biochemistry and Physiology A, vol. 164, pp. 66-70, 2013.

[73] R. Shine and G. P. Brown, "Effects of seasonally varying hydric conditions on hatchling phenotypes of keelback snakes (Tropidonophis mairii, Colubridae) from the Australian wet-dry tropics," Biological Journal of the Linnean Society, vol. 76, no. 3, pp. 339-347, 2002.

[74] D. T. Booth and C. Y. Yu, "Influence of the hydric environment on water exchange and hatchlings of rigid-shelled turtle eggs," Physiological and Biochemical Zoology, vol. 82, no. 4, pp. 382387, 2009.

[75] X. Tang, F. Yue, M. Ma, N. Wang, J. He, and Q. Chen, "Effects of thermal and hydric conditions on egg incubation and hatchling phenotypes in two Phrynocephaluslizards," Asian Herpetological Research, vol. 3, pp. 184-191, 2012.

[76] W.-G. Du and R. Shine, "The influence of hydric environments during egg incubation on embryonic heart rates and offspring phenotypes in a scincid lizard (Lampropholis guichenoti)," Comparative Biochemistry and Physiology A: Molecular and Integrative Physiology, vol. 151, no. 1, pp. 102-107, 2008.

[77] G. C. Packard, "Water relations of chelonian eggs and embryos: is wetter better?" American Zoologist, vol. 39, no. 2, pp. 289-303, 1999.

[78] T. Madsen and R. Shine, "Phenotypic plasticity in body sizes and sexual size dimorphism in European grass snakes," Evolution, vol. 47, pp. 321-325, 1993.

[79] M. A. Krause, G. M. Burghardt, and J. C. Gillingham, "Body size plasticity and local variation of relative head and body size sexual dimorphism in garter snakes (Thamnophis sirtalis)," Journal of Zoology, vol. 261, no. 4, pp. 399-407, 2003.

[80] A. Kaliontzopoulou, D. C. Adams, A. van der Meijden, A. Perera, and M. A. Carretero, "Relationships between head morphology, bite performance and ecology in two species of Podarcis wall lizards," Evolutionary Ecology, vol. 26, pp. 825-845, 2012.

[81] D. J. Irschick, L. J. Vitt, P. Zani, and J. B. Losos, "A comparison of evolutionary radiations in mainland and Caribbean Anolis lizards," Ecology, vol. 78, pp. 2191-2203, 1997.

[82] J. B. Losos, "The evolution of form and function: morphology and locomotor performance in West Indian Anolis lizards," Evolution, vol. 44, no. 5, pp. 1189-1203, 1990.

[83] D. B. Miles, "Covariation between morphology and locomotor performance in sceloporine lizards," in Lizard Ecology. Historical and Experimental Perspectives, L. J. Vitt and E. R. Pianka, Eds., pp. 207-235, Princeton University Press, Princeton, NJ, USA, 1994.
[84] T. Kohlsdorf, T. Garland Jr., and C. A. Navas, "Limb and tail lengths in relation to substrate usage in Tropidurus lizards," Journal of Morphology, vol. 248, no. 2, pp. 151-164, 2001.

[85] T. Garland Jr and J. B. Losos, "Ecological morphology of locomotor performance in squamate reptiles," in Ecological Morphology: Integrative Organismal Biology, P. C. Wainright and S. M. Reilly, Eds., pp. 240-302, University of Chicago Press, Chicago, Ill, USA, 1994.

[86] R. Van Damme, B. Vanhooydonck, P. Aerts, and F. De Vree, "Evolution of lizard locomotion: context and constraint," in Vertebrate Biomechanics and Evolution, V. Bells, J. P. Gasc, and A. Casinos, Eds., pp. 267-282, BIOS Scientific Publishers, Oxford, UK, 2003. 

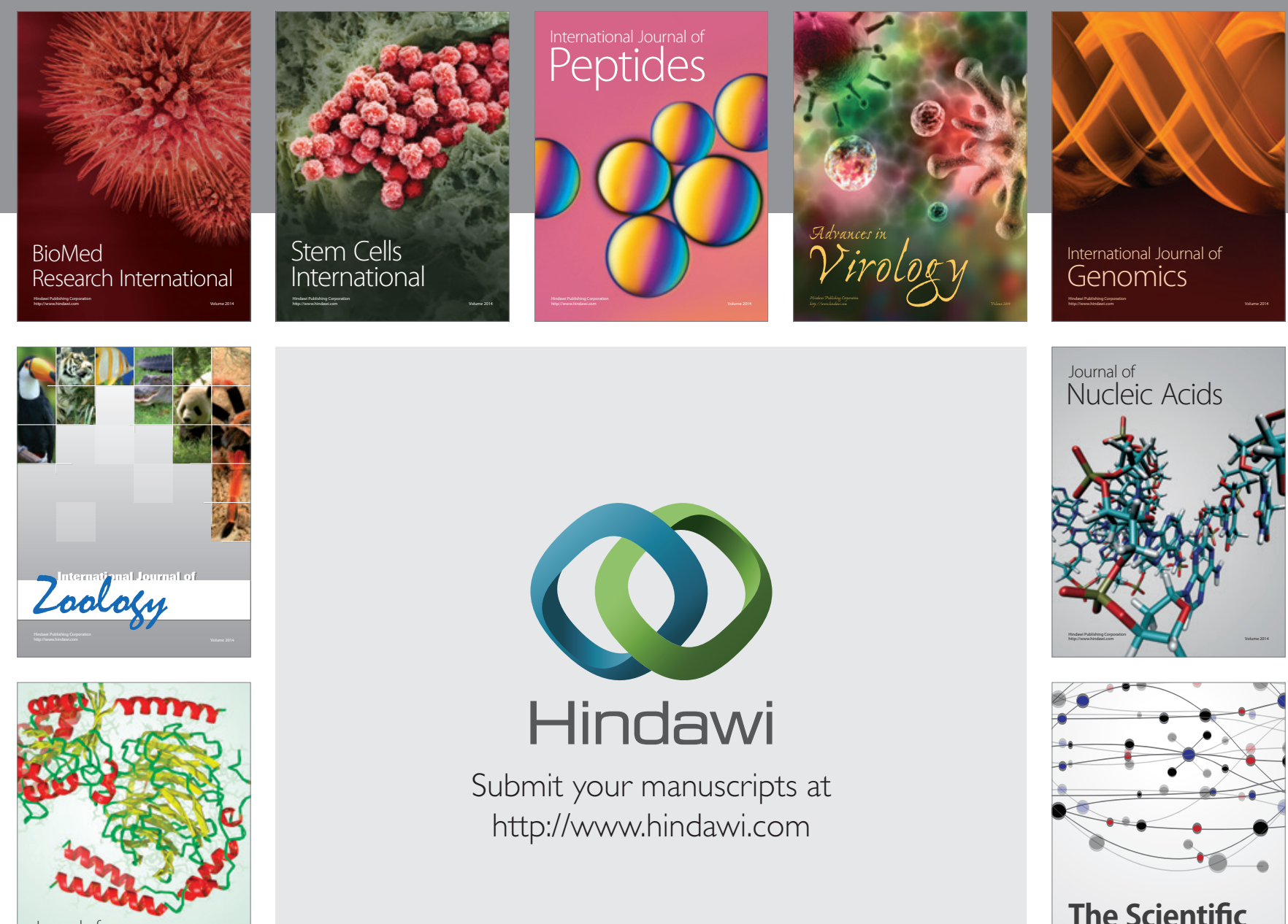

Submit your manuscripts at

http://www.hindawi.com

Journal of
Signal Transduction
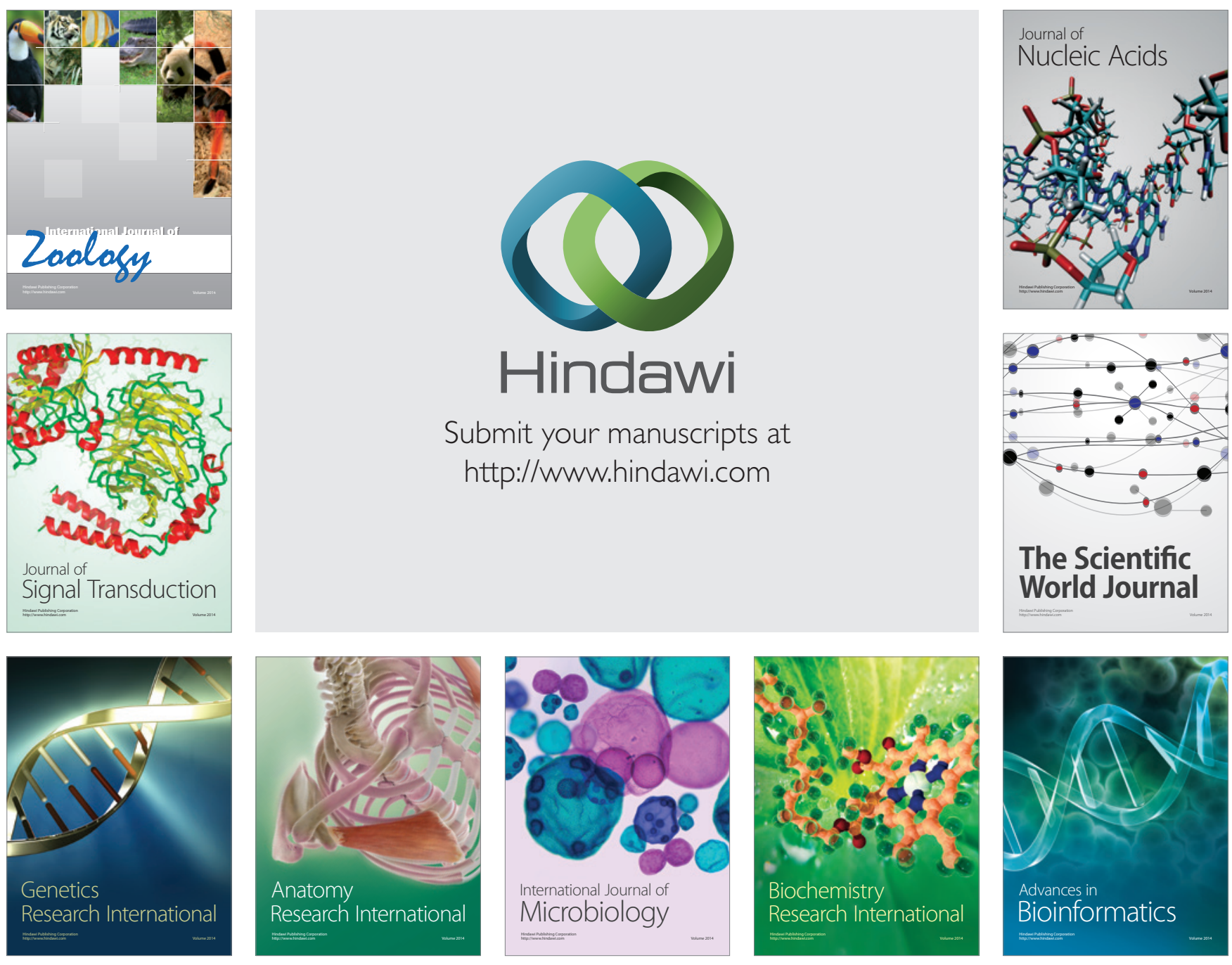

The Scientific World Journal
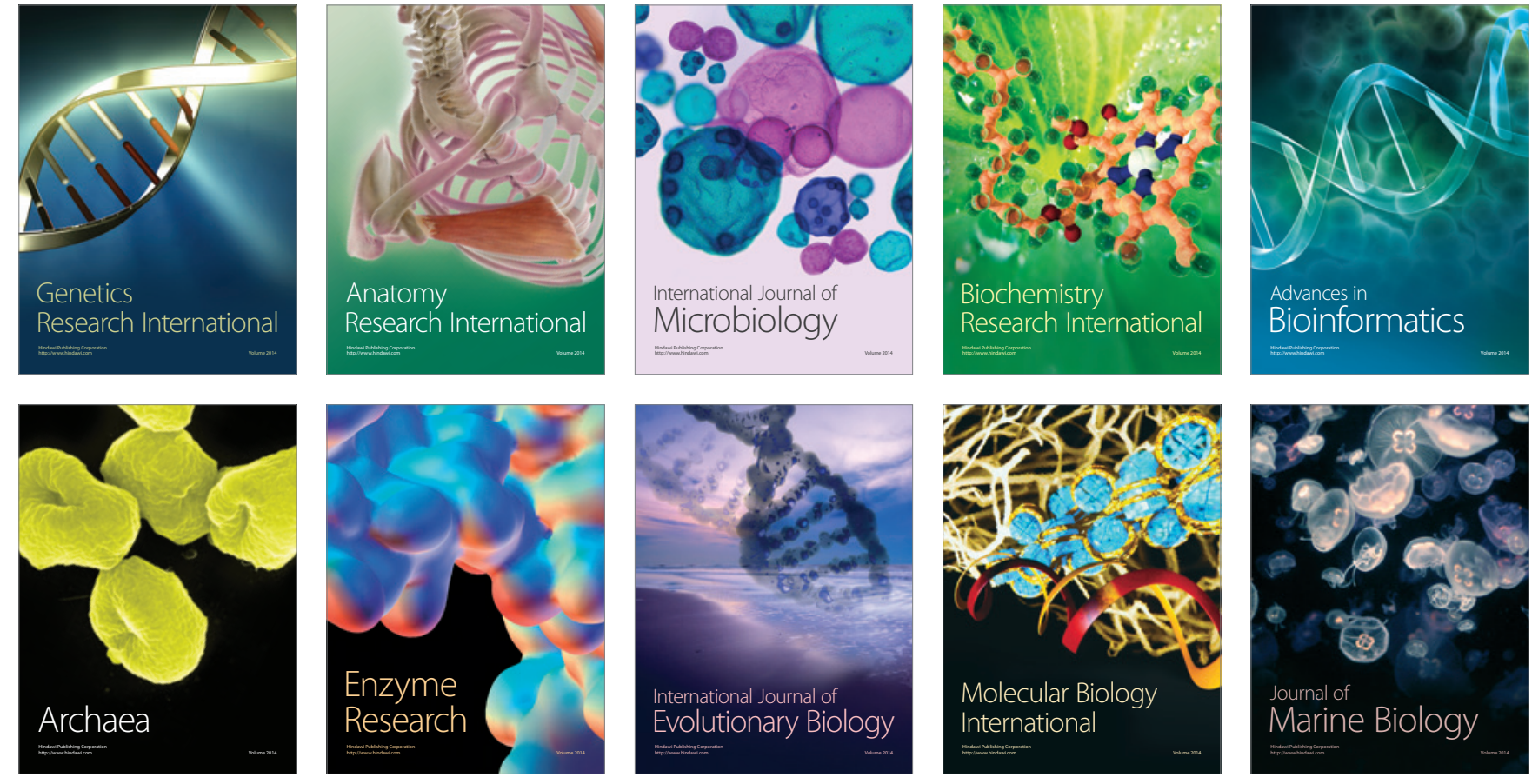